\title{
Temperature Measurement Using Optical Fiber Methods: Overview and Evaluation
}

\author{
Martin Mikolajek (D), ${ }^{1}$ Radek Martinek, ${ }^{1}$ Jiri Koziorek, ${ }^{1}$ Stanislav Hejduk, ${ }^{2}$ Jan Vitasek, ${ }^{2}$ \\ Ales Vanderka, ${ }^{2}$ Radek Poboril, ${ }^{2}$ Vladimir Vasinek, ${ }^{2}$ and Radim Hercik ${ }^{1}$ \\ ${ }^{1}$ Department of Cybernetics and Biomedical Engineering, Faculty of Electrical Engineering and Computer Science, VSB- \\ Technical University of Ostrava, 70800 Poruba, Ostrava, Czech Republic \\ ${ }^{2}$ Department of Telecommunications, Faculty of Electrical Engineering and Computer Science, VSB-Technical University of Ostrava, \\ 70800 Poruba, Ostrava, Czech Republic
}

Correspondence should be addressed to Martin Mikolajek; martin.mikolajek@vsb.cz

Received 20 March 2020; Revised 20 August 2020; Accepted 28 August 2020; Published 12 October 2020

Academic Editor: Qiang Wu

Copyright (c) 2020 Martin Mikolajek et al. This is an open access article distributed under the Creative Commons Attribution License, which permits unrestricted use, distribution, and reproduction in any medium, provided the original work is properly cited.

\begin{abstract}
The paper deals with the overview of fiber optic methods suitable for temperature measurement and monitoring. The aim is to evaluate the current research of temperature measurements in the interval from temperature close to 0 up to $1000^{\circ} \mathrm{C}$. Since the measuring chain is a functional combination of optical methods, optical fiber properties, and other photonic elements together with control electronic circuits, it is necessary to find a suitable compromise between the chosen measurement method, measuring range, accuracy, and resolution. Optical fiber sensors can be used in cases where standard electrical measurement methods cannot be used. These may be areas with high electrical and magnetic interference or critical areas. Therefore, there is intensive development of optical and fiber optic methods based on blackbody and greybody radiation, luminescence, fiber Bragg gratings (FBGs), and interferometers.
\end{abstract}

\section{Introduction}

At present, many fundamentally different ways of measuring high temperatures are used. One of the primary users of temperature measurements is the automotive industry. There are a number of areas where it is necessary to measure or at least monitor this high temperature directly. An overview of some key locations in which the temperature is measured is given in Figure 1. These are, in particular, points in the exhaust pipe, near catalytic converters, or turbochargers. An example of temperature measurement using optical methods is dealt with in the article from Bock et al. [1]. Another article from Jiang et al. is about a temperature fiber sensor for the aviation industry [2].

There are noncontact measurement methods [3] using emitted radiation of the observed body [4], known as temperature measurement by thermal cameras [5-8]. These methods require knowledge of the surface emissivity of the measured bodies. By these methods, surface temperatures of bodies can easily be determined $[5,6]$. In a standard way, however, metallically attached thermocouple or resistive sensors, bimetallic, extensible in volume, and other principles which are connected to the measured object so that they touch it or are located in a space where a given ambient or general fluid temperature is measured, are commonly used in measuring applications. Their typical property is low levels of electrical current or voltage. When designing the measuring chain, account must be taken of the adverse effects of electrical and magnetic disturbances $[9,10]$ on metallic conductors between the actual temperature sensor and the evaluation unit that converts the signal from the sensor to the amplifier or analogue digital converter [10]. In applications where such electrical interference can be expected, it is advisable to use other nonelectrical temperature measurement methods. It is possible to use optical methods using optical fibers and the principles of 


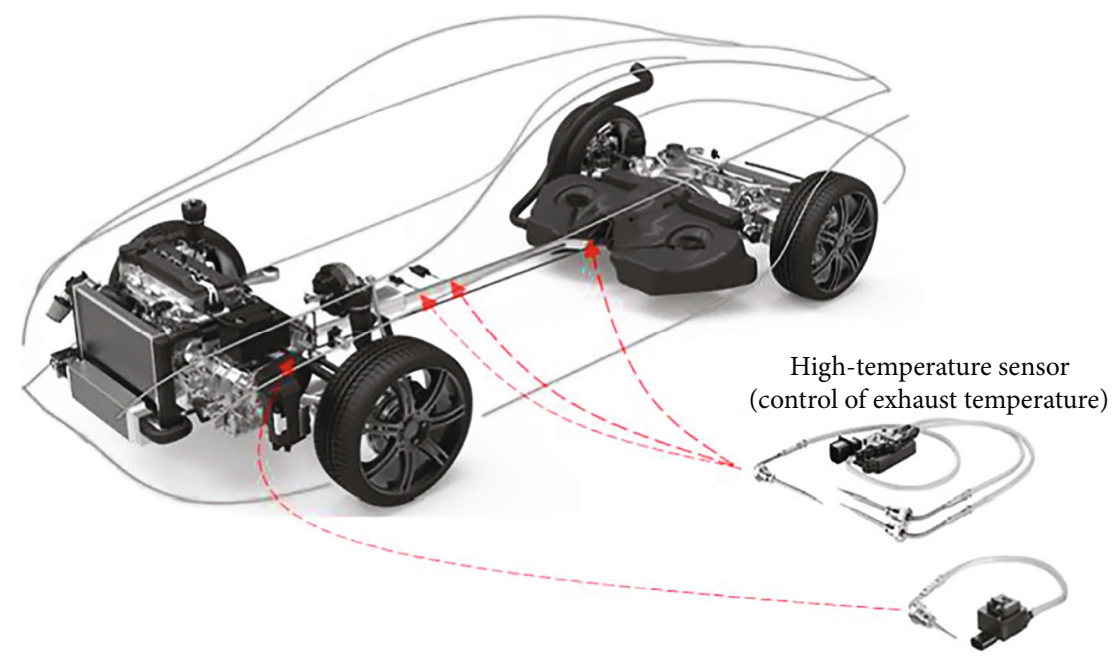

FIgURE 1: High-temperature measurement points in vehicles.

blackbody radiation [11-14], luminescence in crystals [1522], refractive index phenomenon in the fiber Bragg gratings [23-28], or phase shift of two coherent beams in interferometric sensors [29-33].

The use of fiber sensors also offers the possibility of galvanic isolation, which brings the possibility of use in the chemical industry and various explosive environments. The use of fiber sensors for temperature measurement is possible using several physical principles which are described in the individual chapters of this text.

The individual principles of temperature measurement using optical sensors also require their own ways of converting the optical signal to the measured temperature in degrees Celsius. One of the tasks of the paper is to present possible ways of evaluating temperature data. The paper focuses only on optical fiber methods of temperature measurement. The contribution does not include comparison of other optical methods of temperature measurement, such as thermovision.

\section{Types of Temperature Measurement Using Optical Methods}

The method of measurement using optical fiber techniques is based on several fundamental principles. Each measurement method has its specific uses in the range of measuring temperatures, accuracy, etc. (see Table 1). The table shows basic advantages and disadvantages of individual fiber methods.

This article goes on to describe all of the above methods. The blackbody (greybody) radiation method uses optical fiber, one part of which leads to a blackbody at the temperature measurement point. The light output generated by the radiation of the heated blackbody is led from the end of the fiber to the photodetector. According to Donati [11], the detected optical power intensity or spectrum of light received by the photodetector corresponds to the measured temperature according to the recalculations below. This measurement principle is only suitable for high tempera- tures of approximately $500^{\circ} \mathrm{C}$, for the use of special types of photodetectors and optical fibers, and even for lower temperatures of approximately $300^{\circ} \mathrm{C}$. This can be the case of evaluation using a spectrometer or a silicon, InGaAs diode, or PbSe photodiode [11].

The second way of measuring the temperature mentioned in this article is the method using the principle of crystal luminescence [15-20]. The subject deals with the description of individual crystals and analysis of individual results for the tested materials. The fundamental difference from the first method is that this method is not passive but requires a light flux generator. The light from one end of the fiber must fall on the selected luminescent crystal. At the other end of the fiber, the photodetector receives the light signal from the crystal depending on the light generated and the temperature at the desired point of measurement [18]. The dependence of the received light output on the temperature is given in the chapter temperature-dependent crystals. The method described later uses the fiber Bragg gratings [23-25]. The range of applications is considerable today; some textbooks describe the principles of FBG [34] and their applications [35]. The principle of this measurement method lies in the passage of light through the periodically modified optical fiber to produce a periodic or quasiperiodic change in the refractive index of the optical fiber. The last part describes interferometric measurements. These methods measure phase shift between two coherent beams that have travelled the same path in one or two optical fibers. This type of sensor can simultaneously measure different physical quantities, including temperature, since the mechanical parameters of the optical fiber changes with the temperature.

The individual chapters deal with the description of general problems of selected methods and with individual features and possibilities of used parts employed in the described manner. The article presents a comprehensive overview of methods for temperature measurement by optical fiber. 


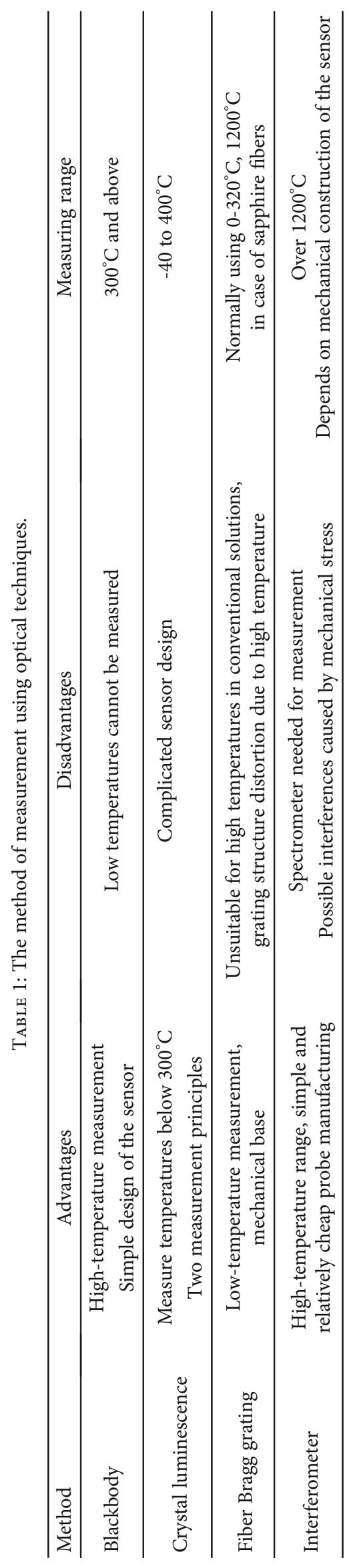




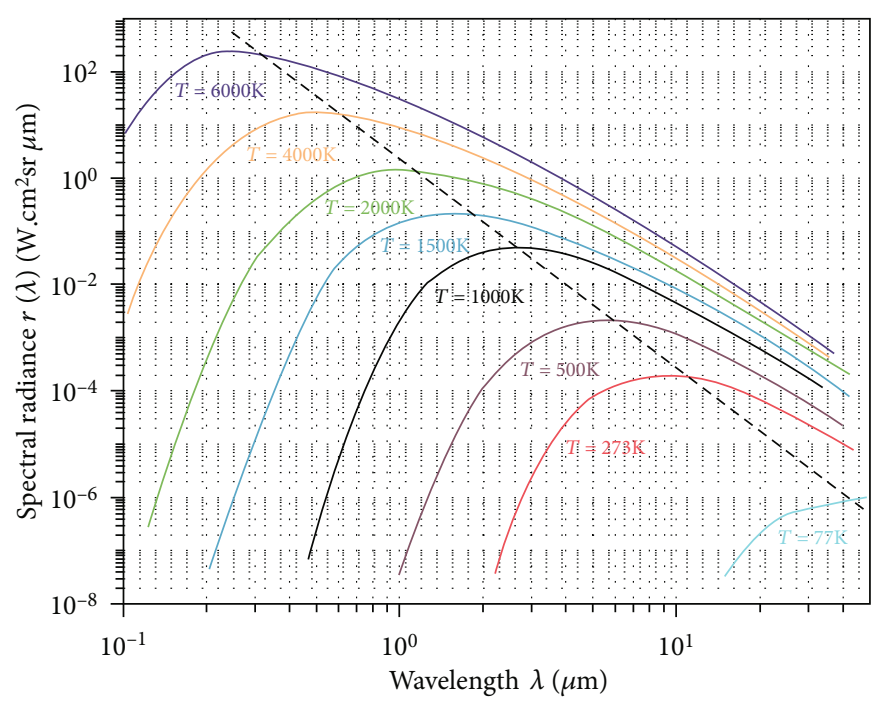

Figure 2: Spectral radiance of the blackbody versus $\lambda$.

\section{Temperature Measurement Using Blackbody Radiation Method}

This method is one of the easiest ways to measure temperature using optical fibers. Only an optical fiber and a suitable photodetector are essential for realization. With minimal financial costs, we are able to assemble a photodetector with a temperature range of approximately 500 to $1200^{\circ} \mathrm{C}$.

Higher temperatures can be measured using a sapphire fiber. For these cases, temperatures up to the melting point of the sapphire fiber can be considered. This means the temperature $2040^{\circ} \mathrm{C}[36,37]$. These boundaries can then be expanded using special components up to the physical limits of fibers and photodetectors.

Each body with nonzero surface temperature emits a certain amount of radiant energy. Most energy is radiated by the so-called black (blackbody radiation, abbreviated as BBR) [38]. The amount of energy and the spectrum of emitted radiation depend only on the surface temperature of the body. Both of these parameters can also be described mathematically by the Planck blackbody emission law, where we can describe the spectral density of the radiation intensity using the following Equation (1), where " $v$ " is given by Equation (2) [11], $h=6.626 \times 10^{-34}$ Js is the Planck constant, $k=1.38 \times 10^{-23} \mathrm{~J} / \mathrm{K}$ is the Boltzmann constant, " $\lambda$ " is the wavelength, " $T$ " is the temperature, and " $c$ " is the speed of light in vacuum $\left(c=3 \times 10^{8} \mathrm{~m} / \mathrm{s}\right)$.

$$
\begin{aligned}
r(\lambda) & =\frac{h v^{2}}{\lambda^{3} e^{h v /(k T-1)}}, \\
v & =\frac{c}{\lambda} .
\end{aligned}
$$

This emitted radiation can easily be used for the optical measurement of the body temperature, where the total radiated energy according to the Stefan-Boltzmann law increases, depending on the absolute temperature with the fourth power (see Equation (3) [11]), where $\sigma$ is the StefanBoltzmann constant according to Equation (4).

$$
\begin{gathered}
E=\sigma T^{4} \\
\sigma=\frac{2 \pi^{5} \cdot k^{4}}{15 c^{2} \cdot h^{4}}=5.670400 \cdot 10^{-8} \mathrm{Js}^{-1} \mathrm{~m}^{-2} \mathrm{~K}^{-4} .
\end{gathered}
$$

The Rayleigh-Jeans law can also be used to measure temperatures if the shortwave spectral region is applied (see Figure 2), from which it is clear that for a suitably chosen wavelength, the radiated energy density at the wavelength interval will be $d \lambda$ as seen below:

$$
r(\lambda) d \lambda=\frac{8 \pi k T d \lambda}{\lambda^{4}}
$$

The second relationship that can be used for the evaluation is Wien's displacement law which says that with the increasing temperature, maximum radiation shifts to shorter wavelengths. In mathematical writing, this fact is expressed by

$$
\lambda_{\max } T=\frac{h c}{4.965 k} .
$$

3.1. Measurement Principle Using Optical Fiber. Information about measured temperature might be transferred through different environments. Vacuum, atmosphere, or other gases are suitable only for Line-Of-Sight (LOS) measurements of blackbody, but for more flexible access to the measured temperature, we can use optical fibers. However, the range of the measured temperatures depends on the spectral sensitivity of the used photodetector and the properties of the transfer medium. When using the optical fiber, the transmission medium is glass, which is quite restrictive in the transmission spectrum. Conventional optical fibers (even low-OH versions) are designed for 


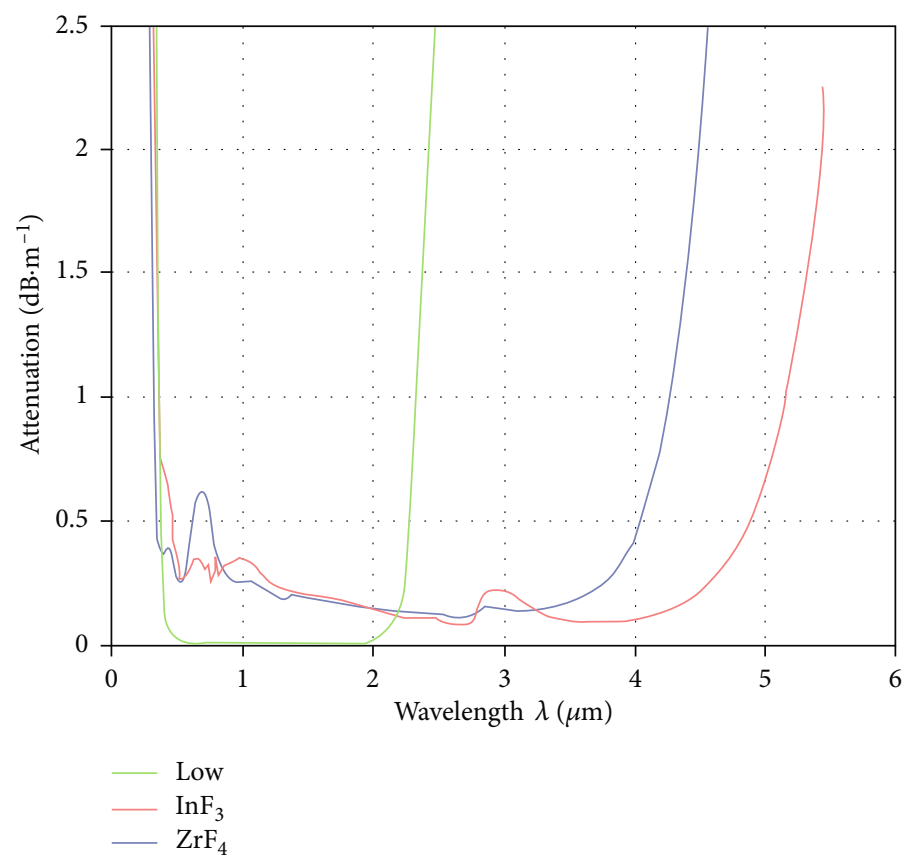

FIgURE 3: Spectral characteristics of optical fibers.

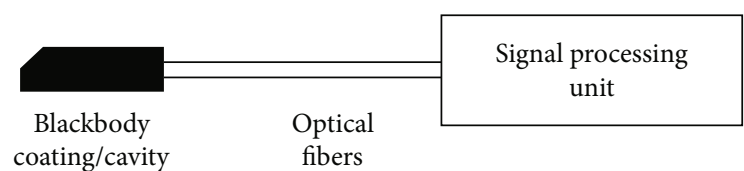

FIGURE 4: Optical fiber deployment for measurement using the blackbody principles.

applications with wavelengths used for communication (i.e., from the visible spectrum to the near infrared range area as shown in Figure 3) [39].

The spectral limit of low-OH optical fibers $(2400 \mathrm{~nm}) \mathrm{can}$ be extended with special fluoride-doped optical fibers ( $\mathrm{InF} 3$ ) [39] or chalcogenide glass. So the spectral limit can be shifted to wavelengths over $5000 \mathrm{~nm}$.

By comparing Figures 2 and 3, theoretically, we can transmit information about temperatures below $0^{\circ} \mathrm{C}$ by an optical fiber. However, in the case of detecting such a signal by a photodetector, we will probably observe few problems in the form of the spectral characteristics of the photodetector (see Figure 6 [11]) and possible external noise. For low temperatures, blackbody radiation is applied not only to the fiber optic signal but also to the optical fiber itself, case, and vicinity of the photodetector. For the successful blackbody measurement of low temperature, the temperature of the measurement optical fiber and photodetector case must be thermally stable; ideally it should be cooler then the measured signal, so the measured energy could be easily detected.

If the measured body does not behave as an absolutely black radiator, its radiation density will be smaller. This reduced proportion is expressed either by the emissivity or by the degree of greyness of the particular body. The degree of greyness indicates how large the percentage of greybody radiation is compared to an absolutely blackbody at the same

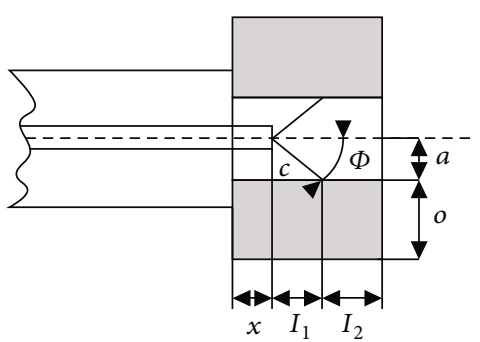

Figure 5: Configuration of the fiber and the blackbody element.

temperature. During the actual measurement, it is necessary to take into account that emissivity is a wavelengthdependent parameter.

The temperature measurement system using the blackbody consists of three parts: optical radiation source approaching the blackbody, optical fiber for signal transmission, and evaluation electronics, shown in Figure 4. The basis for the measurement is to adjust the end of the optical fiber so that its end is as similar to the blackbody as possible. In most cases, this is achieved by means of a metallic coating $[13,14]$ or by inserting a fiber into the measuring pit [12]. The fiber thus captures the blackbody emissions and transmits them to the detector end.

\subsection{Implementation of High-Temperature Measurement} Point (Coating or Cavity). Two basic approaches are used to construct the temperature sensor. Using the coating, the end of the fiber becomes a sensor, and it is thus directly exposed to the measured temperatures during measurement. The coating materials must withstand high temperatures and must not change their emissivity value during repeated cycles. 


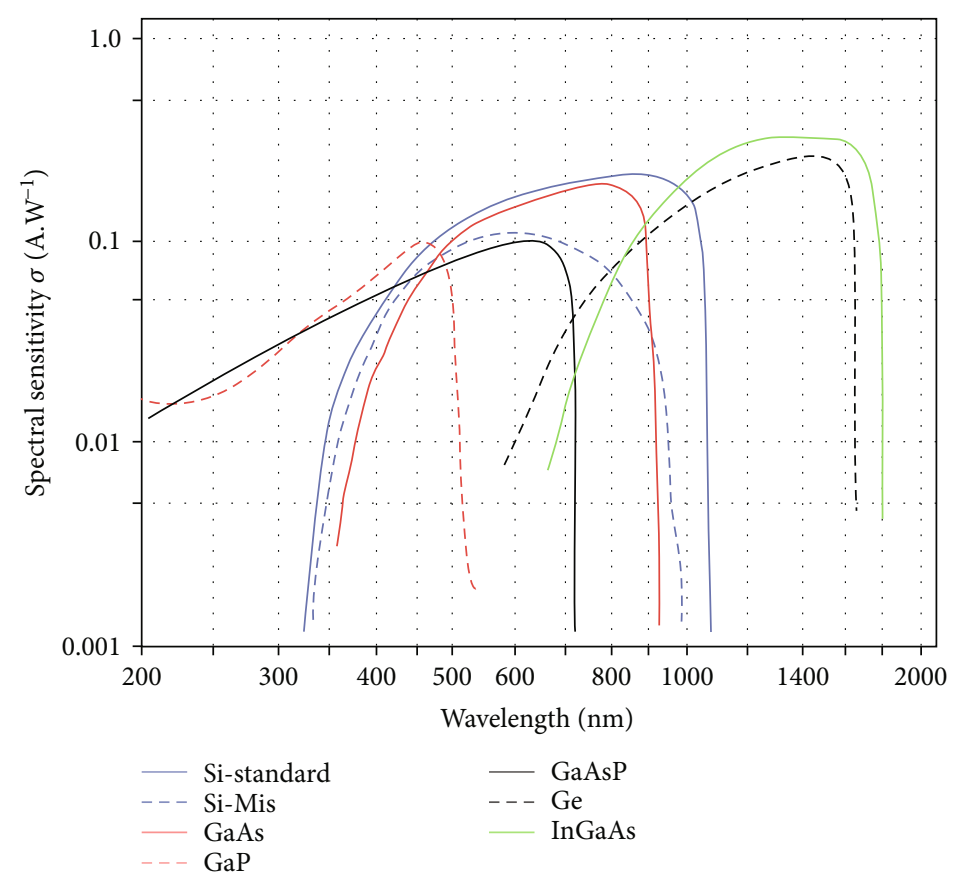

FIGURE 6: Spectral characteristics of photodetectors depending on the composition.

At higher temperatures, however, we cannot leave primary protection on the fiber as the fiber becomes brittle. The sensor produced this way either is not suitable for demanding conditions or must be suitably placed in another temperature-resistant shield.

The cavity provides the fiber with the possibility of protection against adverse environmental influences because the fiber, in this case, does not have to be exposed directly to the measured temperatures. Depending on the shape of the cavity, measurements continue from the end of the fiber. This is given by the value of the acceptance angle at which the fiber collects ambient light and is defined by the numerical aperture (NA) value and the ambient refractive index; see Equation (7) where for air $n=1$, where $\Phi$ is the maximal half-angle of the cone of light that can enter or exit from the optical fiber.

$$
\mathrm{NA}=n \cdot \sin \Phi
$$

Figure 5 [12] shows the effect on the measured area where the energy at the distances $x$ and $l_{1}$ is not connected to the fiber. The measurement is thus mainly focused on the $l_{2}$ area. In principle, the optical fiber in the cavity functions as a noncontact thermometer and retains this property until the fiber optic front is contaminated. Therefore, it is essential that the cavity does not cause evaporation of material due to high temperatures. The situation where the end of the fiber behaves like a grey (black) emitter and it is a source of radiation itself is more common. In this case, the fiber end contamination is not a significant problem.

3.3. Optical Fiber for Blackbody Radiation Method. For measurement, we need to use the fiber to transfer as much optical signal as possible to the detector. Therefore, the optical fiber must have the greatest possible diameter of the core. While keeping the costs low, we can use the $62.5 \mu \mathrm{m}$ MM fiber; however, it is much better to deploy fibers with larger core diameters (e.g., 200 or $300 \mu \mathrm{m}$ ).

The fiber material also directly determines the maximum measurable temperature. As soon as we come close to the melting point, the fiber becomes deformed. Fiber deformations result in a change of the sensor parameters. The melting point of pure $\mathrm{SiO}_{2}$ glass is $1610^{\circ} \mathrm{C}$. This temperature varies depending on the addition agents used. For higher temperatures, it is possible to use sapphire [40] fibers that combine the properties of the sapphire crystal $\mathrm{Al}_{2} \mathrm{O}_{3}$ and optical fiber flexibility. With the melting point of $2045^{\circ} \mathrm{C}$ and chemical properties, they are suitable also for aggressive environments because they are almost chemically neutral.

3.4. Signal Detection for Blackbody Radiation Method. To evaluate the measured temperature, we can use the signal amplitude measurement on the photodiode [40] or evaluate the spectrum of the radiation with a spectrometer [4].

The signal amplitude measurement is simple and inexpensive; however, it provides room for measurement deviations caused, for example, by mechanical and thermal stresses of the fiber.

The lower part of the temperature range is determined in this case by the material of the photodiode used, as can be seen in Figure 6 [11].

When using a silicon $(\mathrm{Si})$ photodiode, the IR portion of the spectrum is limited to about $1000 \mathrm{~nm}$, and at temperatures below $500^{\circ} \mathrm{C}$, the signal amplitude is very small. Another option is the use of InGaAs-based photodiodes, capable of working up to $1800 \mathrm{~nm}$. The applicable temperature range is thus moved up to $300^{\circ} \mathrm{C}$. 


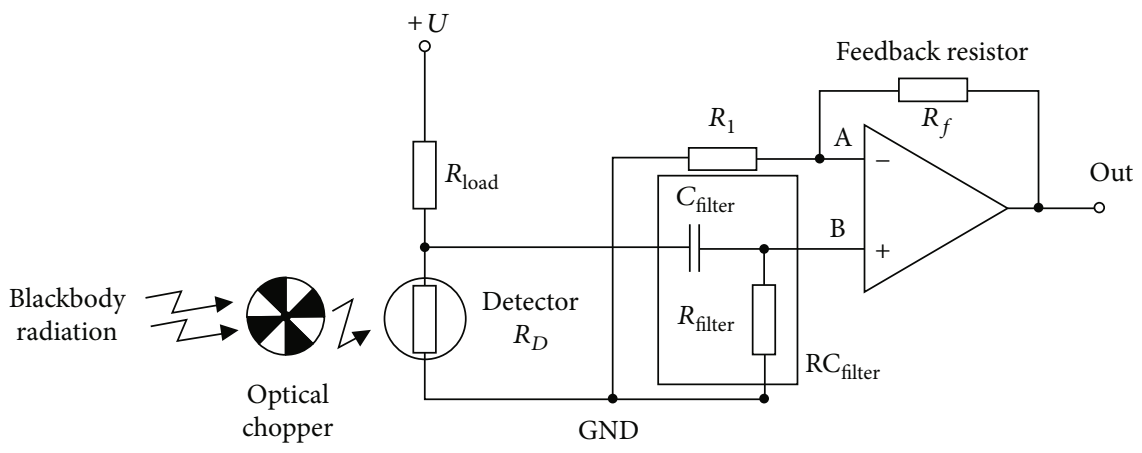

Figure 7: PbSe photoconductor measurement scheme.

The theoretical option is to use InAs [41], a PbSe photoconductive photodetector $[42,43]$ which is capable of detecting wavelengths at the $4800 \mathrm{~nm}$ line, which will allow for further reduction of the working temperature.

However, the measurement procedure differs in this case because this type of detector can process direct current (DC) signals but suffers from a large dark current value that is approximately three orders larger than the InGaAs detectors. To increase the resolving power of the detector, it is necessary to place a mechanical breaker (chopper) as shown in Figure 7 between the detector and the measured signal [44].

\subsection{Measurement Deviations of Blackbody Radiation} Method. BBR measurement results in deviations due to its own emission of radiation from the inside of the optical fiber. If the fiber heats up, its material becomes a source of radiation. The longer the heated portion of the fiber, the greater the manifestations. For signal amplitude evaluation, this deviation can be eliminated, for example, by using the twofiber method shown in Figure 8 [13].

Both fibers are exposed to the same temperature; one is equipped with a blackbody cavity and the other one is covered with reflective coating. As a result, we can eliminate fiber-caused deviations by subtracting individual signals.

3.6. Partial Conclusion for the Blackbody Measurement Methods. The blackbody (greybody) measurement method is particularly suitable because of its simplicity since it requires only a fiber and a suitable photodetector. However, the pitfall of this method lies in the measuring range and accuracy that can be measured by this method; it is particularly suitable for measuring temperatures from $300^{\circ} \mathrm{C}$ to temperatures which depend on the softening or melting temperature of the deployed optical fiber, which may be up to $2000^{\circ} \mathrm{C}$. For lower temperatures, it is possible to use optical fibers in primary or secondary protection and only bare fibers for high temperatures. The disadvantage of this method, however, lies in the complicated measurement of temperatures below the temperatures lower than $600^{\circ} \mathrm{C}$. The measuring areas can be influenced by the type of photodetector used, especially for the lower temperature limit. In these cases, it is always necessary to use special photodetectors, then the price of the overall measuring chain increases. For still decreasing temperature ranges, the instability and inaccuracy of the measuring chain are increasing. This is due to the fact that

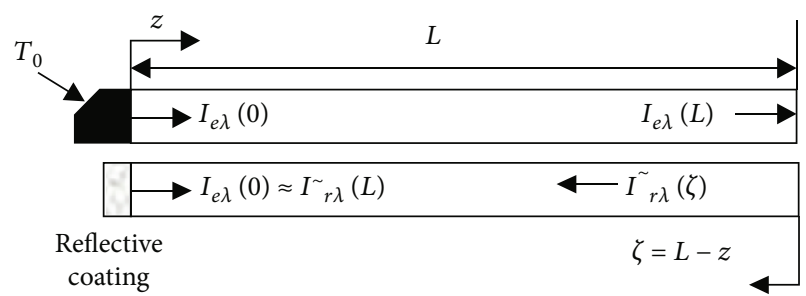

Figure 8: Two-fiber optical thermometer.

when the temperature at the measuring point approaches the temperature of the photodetector, the received signal begins to be "drowned" in noise.

\section{Luminescent Crystals with Temperature Dependence}

Some crystal parameters show dependence on ambient temperature due to their composition. The parameter showing the temperature dependence is primarily luminescence. In luminescence, we can measure the excited spectrum, excited light intensity, or the lifetime of electrons in the excited state. Luminescence time response measurement is the most commonly used method because it is relatively simple and intensely independent of the amount of excited light [15, 45]. Crystals showing the temperature dependence of the lifetime of excited light-generating electrons are ruby (chromium-doped sapphire) [15-20], alexandrite $[15,16,19,46$, 47], Cr:LiSAF [15, 16, 19, 48, 49], Cr:YAG, or $\mathrm{Nd}^{3+}: Y A G$ $[15,16,19,21,50]$. Ruby is a chromium-doped aluminium oxide $\left(\mathrm{Cr}^{3+}: \mathrm{Al}_{2} \mathrm{O}_{3}\right)$. Chromium atoms, due to the similar size, can replace the aluminium atoms in the $\mathrm{Al}_{2} \mathrm{O}_{3}$ crystal lattice. Due to the presence of chromium, a phenomenon known as fluorescence occurs after absorbing the excitation light.

4.1. Description of Fluorescence. After delivery of the excitation light, the electrons move to the energy level of ${ }^{4} T_{2}$, where they, however, do not hold and pass to the metastable level of ${ }^{2} E$. Thanks to spin-orbit coupling [51], the metastable level of ${ }^{2} E$ is divided into two levels of ${ }^{-} E$ and ${ }^{2-} A$ with the energy difference $\Delta E$. This division of the metastable level causes the formation of two emission spectral lines. The first emission spectral line $R_{1}$ is due to the transition of ${ }^{-} E \geq 4 A_{2}$ $(694.3 \mathrm{~nm})$; the second emission spectral line $R_{2}$ is due to 


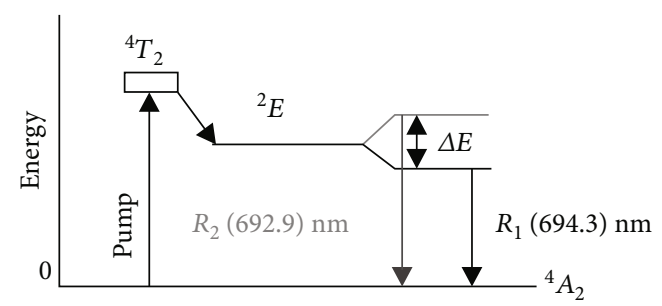

FIgURe 9: Simplified diagram of ruby energy levels.

the transition of ${ }^{2-} A \geq{ }^{4} A_{2}(692.9 \mathrm{~nm})$. The second emission spectral line $R_{2}$ is slightly weaker than the first $R_{1}[18,52]$. A simplified diagram of the energy levels of ruby is shown in Figure 9.

Fluorescence is time-dependent, and after switching off the excitation light after a certain period of time called the lifetime, it disappears.

For this reason, the excitation light source must be modulated by a rectangular pulse, thus alternately turning the excitation light on and off. The lifetime of the emission spectral line $R_{2}$ is $\sim 3-3.5 \mathrm{~ms}$ and $R_{1}$ is $\sim 0.6 \mathrm{~ms}[15,18]$.

Changing the temperature leads to a change in the coupling (tension) in the crystal lattice and the distribution of phonons and energy, and consequently, it influences the fluorescence lifetime of ruby. The relatively short lifetime at the ${ }^{4} T_{2}$ level causes the fluorescence of $R$ lines to dominate due to the long-lasting ${ }^{2} E$ level at low temperatures (transition ${ }^{2} E \rightarrow{ }^{4} A_{2}$ determines the temperature dependency of the lifetime). At room temperature (about $300 \mathrm{~K}$ ) the lifetime is about $\sim 3.5 \mathrm{~ms}[15,18]$. With increasing temperature, some $\mathrm{Cr}^{3+}$ ions are propped up to revert to the ${ }^{4} T_{2}$ level from the ${ }^{2} E$ level rapidly. With further increases in the temperature, more and more ions are propped up to this reversion, thereby emptying the ${ }^{2} E$ level and the nonradiant transitions ${ }^{4} T_{2}$ $\rightarrow{ }^{4} A_{2}$ start to dominate. Significant loss of radiant transitions thus reduces the lifetime of fluorescence to $\sim 1 \mu \mathrm{s}$ at a temperature of about $600^{\circ} \mathrm{C}$ [15]. At the same time, the fluorescence-emitted light intensity decreases.

Figure 10 describes the radiant transitions of $\mathrm{Cr}^{3+}$ ions from the ${ }^{2} E \rightarrow{ }^{4} A_{2}$ level at low temperatures where the nonradiant transitions from the ${ }^{4} T_{2}$ level are negligible due to the preferred occupancy of the ${ }^{2} E$ level. With an increasing temperature, the nonradiant transitions ${ }^{4} T_{2} \rightarrow{ }^{4} A_{2}$ start to dominate, the level ${ }^{2} E$ becomes a temporary level for the excitation of ions at the ${ }^{4} T_{2}$ level. The transition time ${ }^{2} E \rightarrow$ ${ }^{4} T_{2}$ is around $\sim 7 \mathrm{ps}$. The temperature dependence of the fluorescence lifetime can be expressed by [53]

$$
\tau=\tau_{S} \frac{1+C_{d} e^{-(\Delta E / k T)}}{1+\left(\tau_{S} / \tau_{i}\right) e^{-(\Delta E / k T)}}=\tau_{S} \frac{1+3 e^{-(\Delta E / k T)}}{1+\alpha e^{-(\Delta E / k T)}},
$$

where $\tau$ is the fluorescence lifetime, $\Delta E$ is the energy difference between the levels ${ }^{4} T_{2}$ and ${ }^{2} E, \tau_{i}$ and $\tau_{s}$ are the lives of transitions from the ${ }^{4} T_{2}$ and ${ }^{2} E$ levels, $k$ is the Boltzmann constant, $T$ is the temperature, and $C_{d}$ is the ratio of degeneration ${ }^{4} T_{2} /{ }^{2} E[54]$.

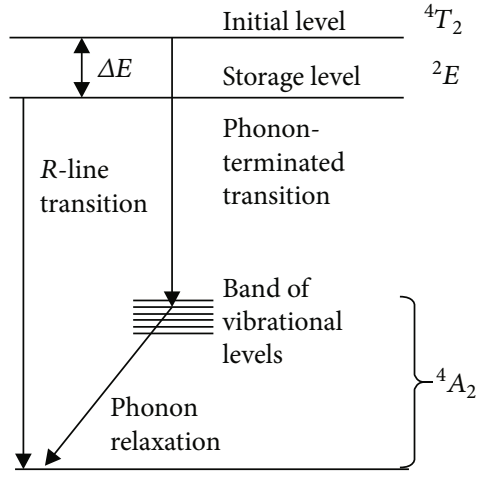

Figure 10: Two-level ruby model.

This model provides good results compared to measurements for temperatures ranging from 300 to $570 \mathrm{~K}$ [54].

From the room temperature to about $\sim 550 \mathrm{~K}$, the lifetime is decreasing. Beyond the $\sim 600 \mathrm{~K}$ limit, the ${ }^{4} T_{2} \rightarrow{ }^{4} A_{2}$ transitions start to dominate, resulting in a rapid drop in the lifetime with an increasing temperature, which Equation (6) already cannot describe accurately enough.

The selected article describes a simplified model for ruby that predicts changes in lifetime with changing temperatures, as shown in Figure 11 [18]. This model includes the radiant ${ }^{2} E \rightarrow{ }^{4} A_{2}$ and nonradiant ${ }^{4} T_{2} \rightarrow{ }^{4} A_{2}$ transitions. The schematic diagram of this model is shown in Figure 10. The lifetime of fluorescence is described by

$$
\tau=\tau_{S} \frac{1+3 e^{-(\Delta E / k T)}}{1+\alpha e^{-(\Delta E / k T)}+\beta e^{-\left(\Delta E_{q}+\Delta E\right)}},
$$

where $\tau_{q}$ is the nonradiant transition, $\Delta E_{q}$ is the energy difference between ${ }^{4} T_{2}$ and ${ }^{4} A_{2}, \alpha=\tau_{s} / \tau_{i}$, and $\beta=\tau_{s} / \tau_{q}$. This model is accurate from 300 to $800 \mathrm{~K}$ with a tolerance of $\sim 1 \%$ over the given temperature range.

4.2. Absorption Spectrum. Although the absorption spectrum of ruby is strongly dependent on the polarization of the excitation light $[18,55]$, there are relatively small differences between the intensities $R_{1}$ and $R_{2}$.

The absorption spectrum of ruby is spectrally broad, as shown in Figure $12[15,18]$. There are two absorption peaks around 410 and $550 \mathrm{~nm}$. The emission spectrum has the main peaks, $694.3 \mathrm{~nm}\left(R_{1}\right)$ and $692.9 \mathrm{~nm}\left(R_{2}\right)$.

4.3. Dimensions of Crystals. Hu et al. [16] compare the lifetime of ruby luminescence for two sizes, for a smaller and a larger crystal. Measurements were conducted at temperatures ranging from 77 to $800 \mathrm{~K}$. At the initial temperature, the lifetime of the small crystal fluorescence was $4.2 \mathrm{~ms}$, while the lifetime of the large crystal fluorescence was $7.1 \mathrm{~ms}$. This phenomenon occurs because the fluorescence light is reabsorbed in the large crystal and reexcitation occurs, thus extending the lifetime of fluorescence as the crystal radiates longer. This phenomenon, however, applies to low temperatures; from the temperature of about $0^{\circ} \mathrm{C}$, the fluorescence lives balance out for small and large crystals. However, for 


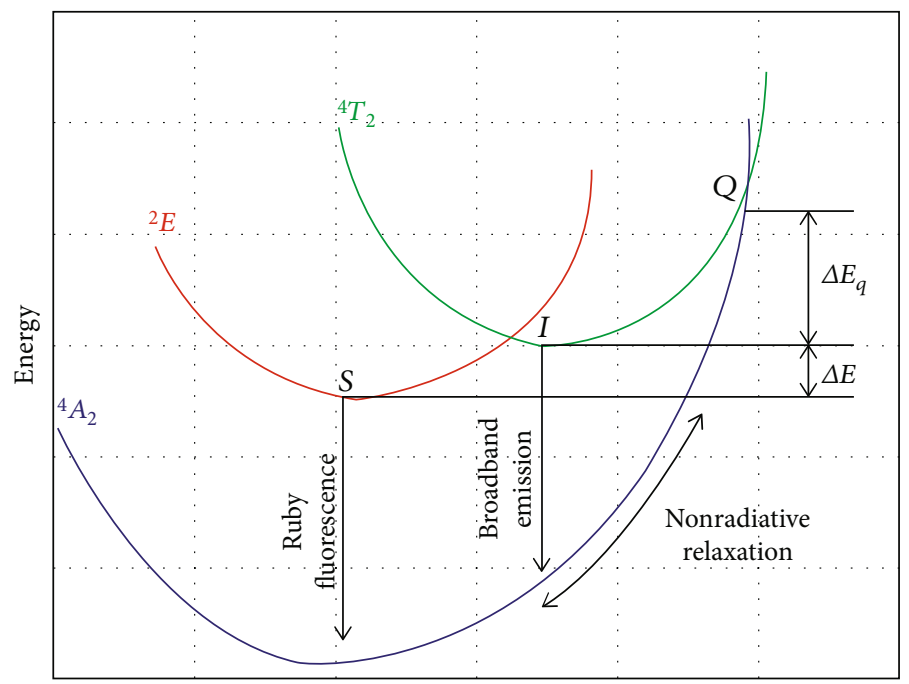

FIgUre 11: A simplified model for ruby.

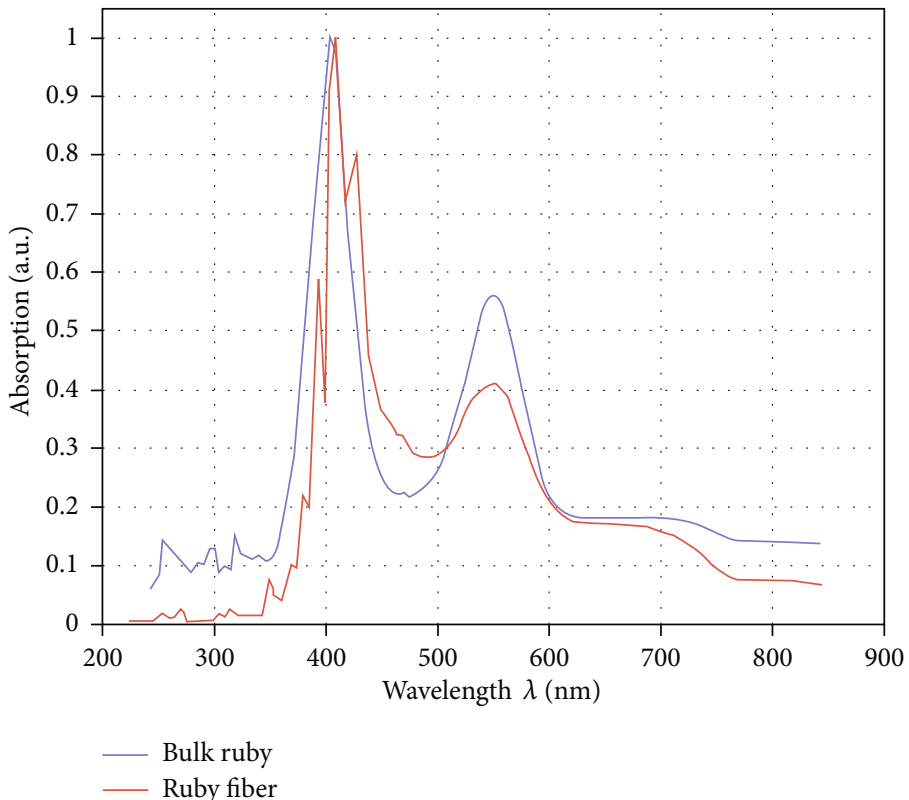

FIGURE 12: Ruby absorption spectrum.

practical applications, it is recommended that the ruby crystal size be as small as possible, just to minimize the redistribution of fluorescent light [16].

4.4. Concentration of Chromium in the Crystal. The fluorescence lifetime is independent of the concentration of chromium in ruby up to the critical level of about $\sim 0.3 \mathrm{wt} . \%$ [56]. Higher chromium concentrations lead to a decrease in the fluorescence intensity. Additionally, over the concentration of $\sim 1 \mathrm{wt} . \%$, the lifetime is no longer simply exponential, as shown in Figure 12 [19].

4.5. Luminescent Experiments. Seat et al. [15] excited ruby using a laser diode with a modulated rectangular signal with a wavelength of $635 \mathrm{~nm}$ that flashed through the fiber optic $(100 / 140 \mu \mathrm{m})$ through a $1 \times 2$ fiber coupler. The optical fiber was coupled to a ruby crystal using a silica glass tubing, both ends of which were melted, thus combining the fiber with the crystal. The sensor thus created was placed in a temperature-controlled furnace with a type $\mathrm{K}$ control thermocouple. The radiated fluorescence light was captured with the same optical fiber and passed through the coupler to the photodiode (APD:Si). A band filter $>$ $670 \mathrm{~nm}$ was placed before the photodetector, which filtered the excitation light. The phase-locked detection (PLD) technique [57] was used to measure the ruby crystal fluorescence lifetime. The detected signal was processed to produce a recurring signal whose period was directly proportional to the time of the lifetime. This reduces the effect of the excitation light, allowing high-resolution 


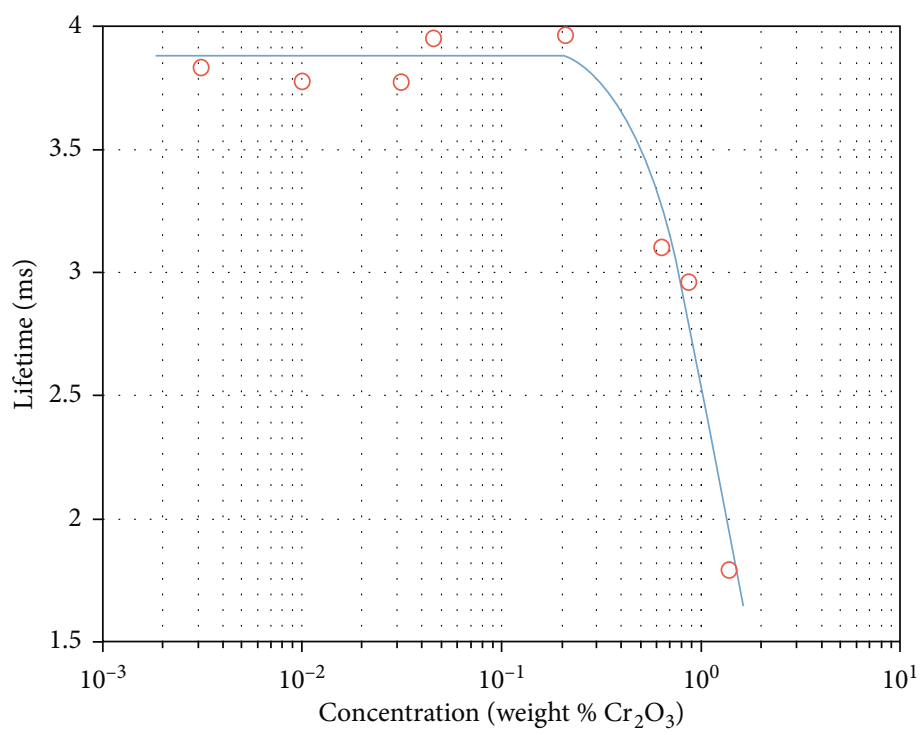

FIgURE 13: Chromium concentration in ruby.

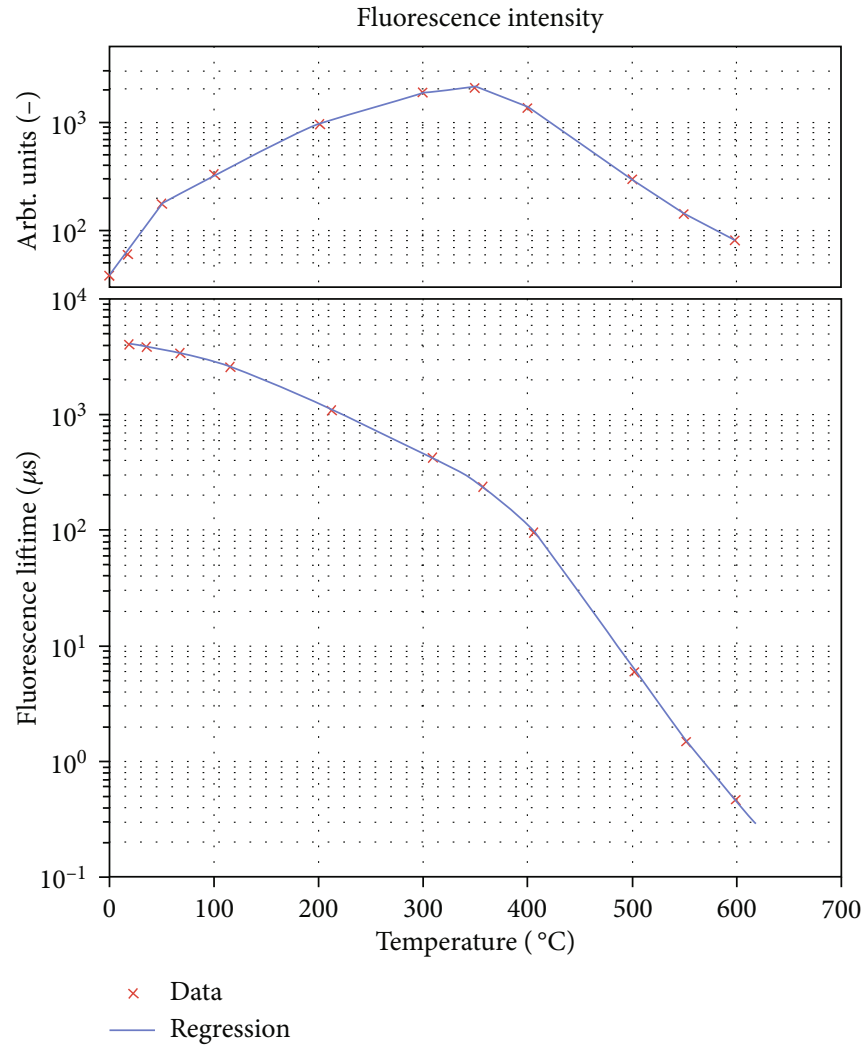

FIgURE 14: Ruby fluorescence.

measurements over a wide temperature range. The lifetime of ruby fluorescence was measured in the temperature range from 0 to $600^{\circ} \mathrm{C}$. Around the temperature of $400^{\circ} \mathrm{C}$, there was a strong drop in fluorescence. The measurement time interval was $1 \mathrm{~s}$, with a resolution of $0.2^{\circ} \mathrm{C}$. The results are shown in Figure 13 [15]. The following Figure 14 shows ruby fluorescence.
$\mathrm{Hu}$ et al. [16] created two ruby temperature sensors, one large $(0.5 \times 0.5 \times 2 \mathrm{~mm})$ and the other small $(0.3 \times 0.3 \times 0.05 \mathrm{~mm})$. These crystals were excited with a He-Ne laser $(5 \mathrm{~mW})$ with a wavelength of $543.5 \mathrm{~nm}$, which emitted continuous light; subsequently, this light was modulated by an acoustic-optical modulator (AOM) to rectangular pulses. As in the previous case, a $1 \times 2$ fiber 


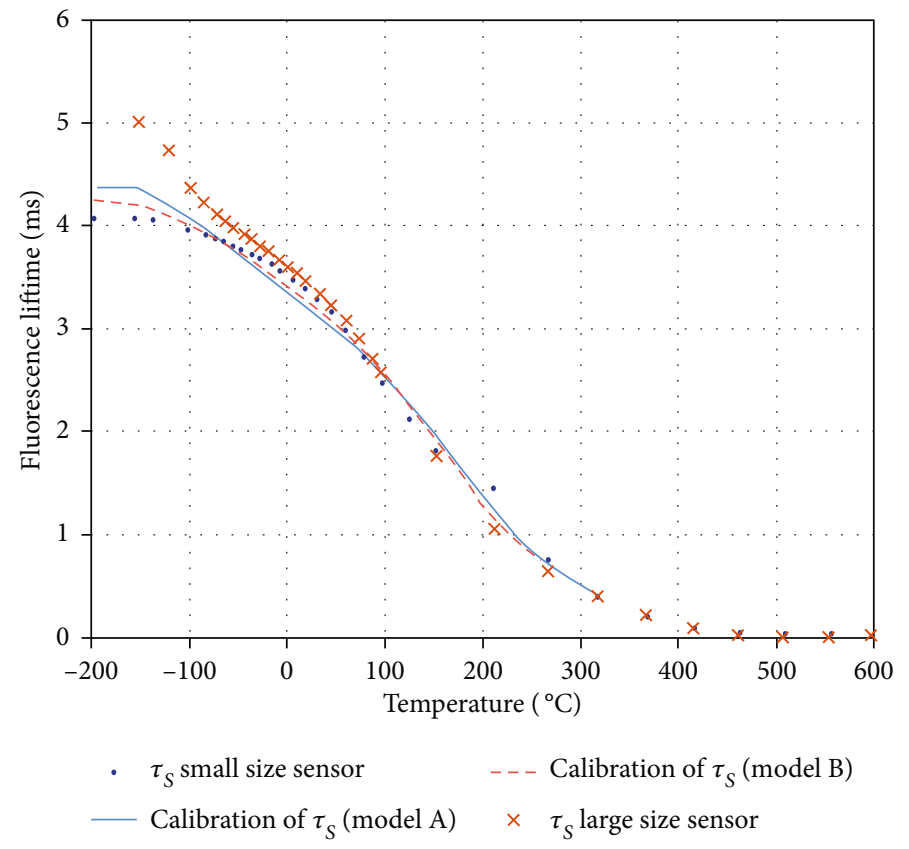

Figure 15: Ruby fluorescence with two crystals of a different size.

TABLE 2: The method of measurement using optical techniques.

\begin{tabular}{lccccccccc}
\hline$T(\mathrm{~K})$ & 292 & 295 & 323 & 373 & 374 & 375 & 423 & 473 & 523 \\
$\tau(\mathrm{ms})$ & 3.420 & 3.420 & 3.160 & 2.680 & 2.670 & 2.660 & 2.120 & 1.590 & 1.160 \\
$T(\mathrm{~K})$ & 573 & 574 & 623 & 673 & 723 & 773 & 823 & 873 & 923 \\
$\tau(\mathrm{ms})$ & 0.842 & 0.839 & 0.615 & 0.435 & 0.289 & 0.153 & 0.082 & 0.050 & 0.045 \\
\hline
\end{tabular}

coupler was used. In addition, an optical fiber with a diameter of $0.4 \mathrm{~mm}$ for a large sensor and a fiber with a diameter of $0.1 \mathrm{~mm}$ for a small sensor were used. Both threads had protection made of gold to withstand low temperatures. The crystals were also protected by the gold shield. The fibers and crystals were joined by a high-temperature adhesive. Fluorescent light was fed to an avalanche photodetector (APD). An optical filter $(>690 \mathrm{~nm})$ was placed before the photodetector to remove the excitation light. Measurements took place in the temperature range of 77 to $800 \mathrm{~K}$ $\left(-196\right.$ to $\left.527^{\circ} \mathrm{C}\right)$ with both sensors, so the effect of ruby crystal size on the fluorescence lifetime can be observed [16]. Figure 15 shows ruby fluorescence with two crystals of a different size.

Seat and Sharp [18] used a ruby crystal at a concentration of 0.1 wt.\%. This crystal was connected to an optical fiber having a core diameter of $0.2 \mathrm{~mm}$. The fiber and crystal were connected by means of a conical glass roller, at both ends of which a high-temperature ceramic adhesive was used, which joined a glass roller with a ruby at one end and an optical fiber at the other end. This sensor was inserted into a temperature-controlled furnace. The excitation light emanating from the $\mathrm{Ar}^{+}$laser $(514.5 \mathrm{~nm})$ was modulated before entering the $1 \times 2$ fiber coupler. The excited light was fed to an avalanche photodiode in front of which there was an optical narrowband interference filter $(694 \mathrm{~nm}$, full width at half maximum $(\mathrm{FWHM}) \pm 2 \mathrm{~nm})$ to remove the excitation light. Fluorescence lifetime measurements were carried out within the temperature range from 292 to $923 \mathrm{~K}\left(19\right.$ to $\left.650^{\circ} \mathrm{C}\right)$ with a step of $50 \mathrm{~K}$. Very good results were achieved up to a temperature of $773 \mathrm{~K}\left(500^{\circ} \mathrm{C}\right)$ when the standard deviation for this temperature was $0.32 \%$, providing an $\sim 2.4 \mathrm{~K}$ resolution. The accuracy of measurements at higher temperatures $\left(>500^{\circ} \mathrm{C}\right)$ deteriorates due to the low fluorescence signal from ruby. The maximum deviation of the measurement was recorded at a maximum temperature of $923 \mathrm{~K}$, namely, $\sim 4.6 \%$. The expected relatively long lifetime of fluorescence $(\sim 2-3 \mathrm{~ms})$ was measured at low temperatures up to $600 \mathrm{~K}$ $\left(327^{\circ} \mathrm{C}\right)$, then the lifetime decreased below $1 \mathrm{~ms}$ due to the increasing dominance of nonradiant transitions and heat extinction. The measured results of the fluorescence lifetime at different temperatures are shown in Table 2 [18]. Ruby fluorescence is shown in Figure 16.

Similar measurements can also be found in another publication [19]. For measurement, gold-coated quartz fiber with a core diameter of $400 \mu \mathrm{m}$ was used. This sensor has been tested from 30 to $550^{\circ} \mathrm{C}$. As expected, the fluorescence lifetimes were decreasing with an increasing temperature. Beyond $500^{\circ} \mathrm{C}$, the fluorescence lifetime was essentially stabilized. The measurement results are shown in Figures 17 and 18.

Obviously, the individual measurements are related to the types of crystals that are used for the measurements. 


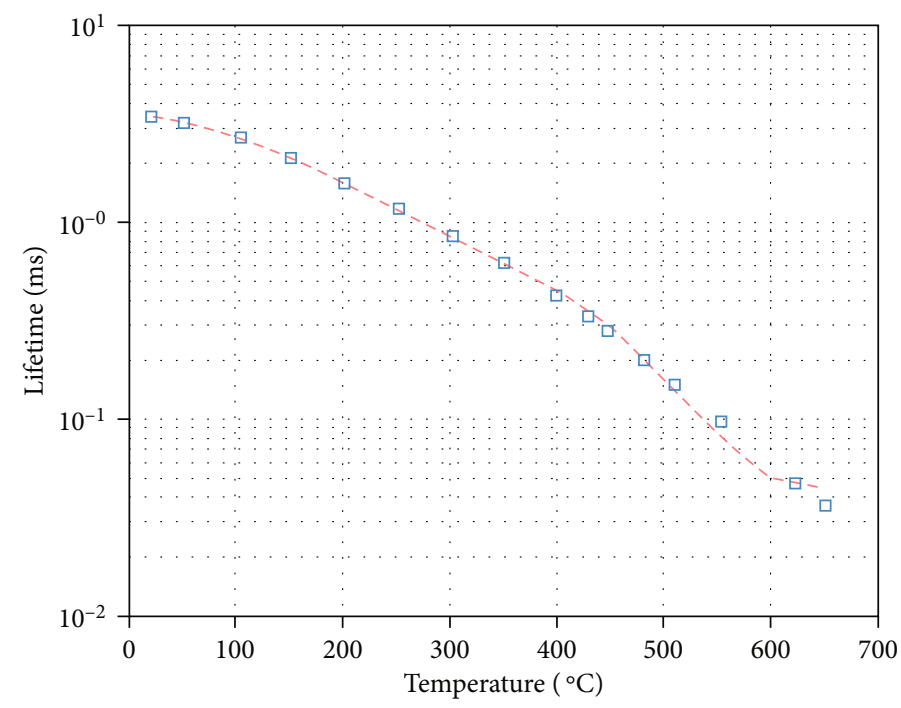

- Experimental data

- - SCC model

Figure 16: Ruby fluorescence.

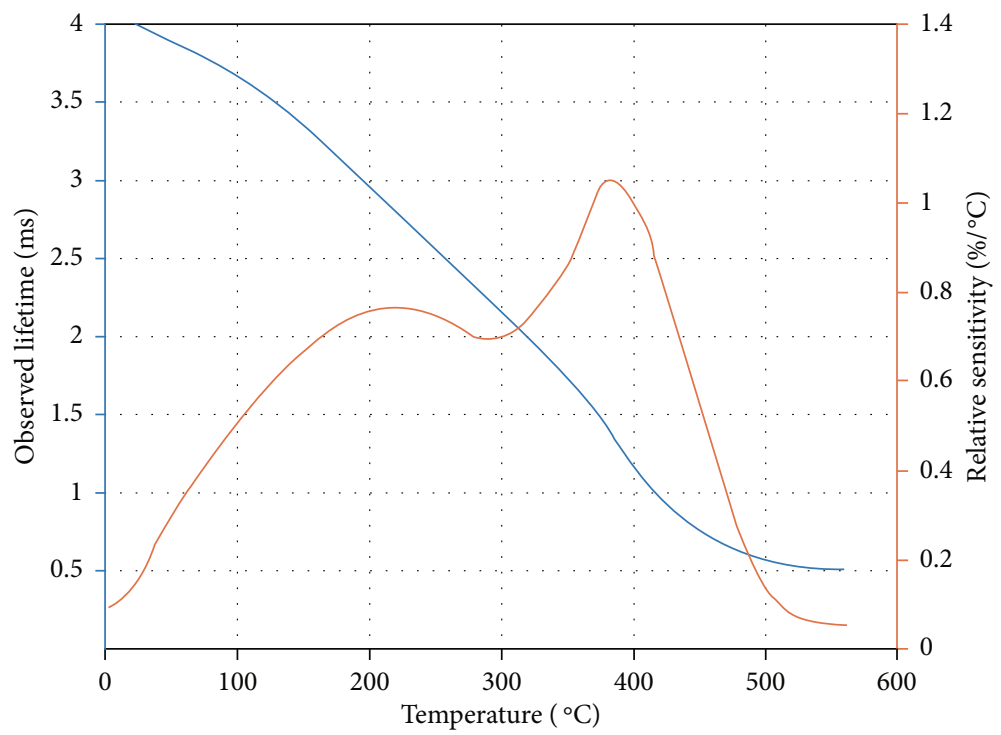

FIGURE 17: Ruby fluorescence lifetime.

The following part of the article deals with the analysis of crystalline materials using luminescence measurements.

4.6. Luminescent Material Alexandrite. Similar properties are shown by alexandrite which is hence used as a ruby. Alexandrite has a different absorption spectrum (see Figure 18 [47] with respect to ruby); therefore, it is excited by another light source. To excite alexandrite, a $670 \mathrm{~nm}$ [46] or $633 \mathrm{~nm} \mathrm{He}-\mathrm{Ne}$ laser was deployed. Zhang et al. [47] set up a temperature sensor based on the fluorescence lifetime measurement like in the case of ruby. They performed measurements from 0 to $700^{\circ} \mathrm{C}$, the results of which are shown in Figure 19 [19]. The lifetime of alexandrite fluorescence is shorter at room temperatures $(300 \mu \mathrm{s})$ than in the case of ruby $(\sim 3.5 \mathrm{~ms})$.
Alexandrite can be produced artificially, as well as ruby, using the Czochralski method [58]. Additionally, alexandrite can be found in nature; it is mined in Brazil, Ural, Tanzania, Madagascar, and India [59].

4.7. Luminescent Material Cr:LiSAF. The material Cr:LiSAF is useful for temperature measurement in biomedical applications $\left(30-50^{\circ} \mathrm{C}\right)$. Again, the fluorescence lifetime measurement is used. Zhang et al. [48] used a Cr:LiSAF laser with a wavelength of $670 \mathrm{~nm}$ for exciting. The excitation light was coupled to a quartz optical fiber (core $200 \mu \mathrm{m}$ ) through a 1 $\times 2$ fiber coupler. At the end of the optical fiber, a Cr:LiSAF sample was attached using an adhesive. In front of the photodetector, the optical filter was deployed to suppress the 


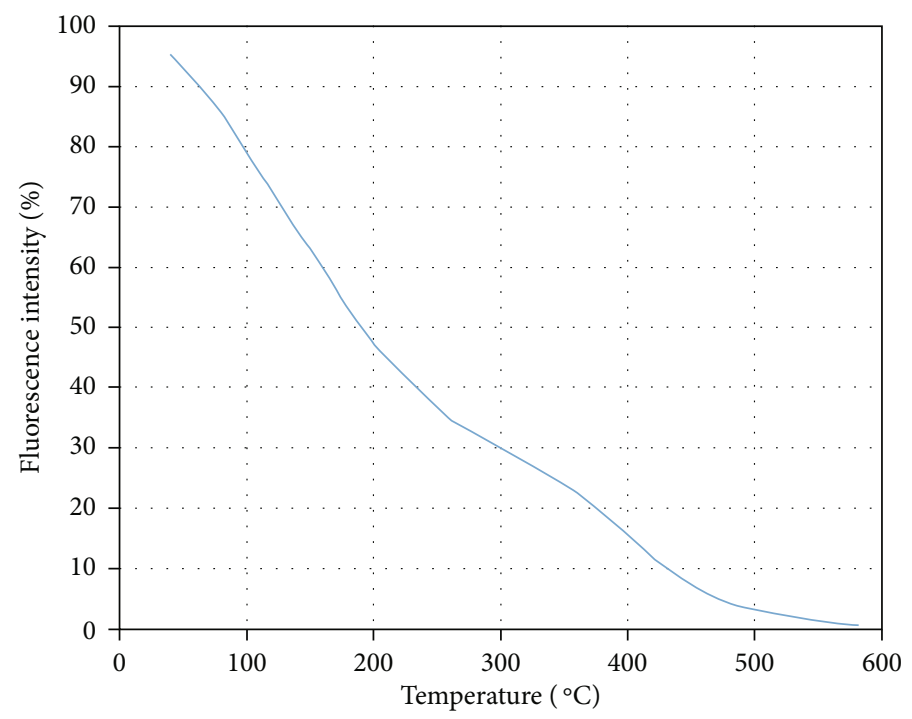

FIGURE 18: Intensity of ruby fluorescence.

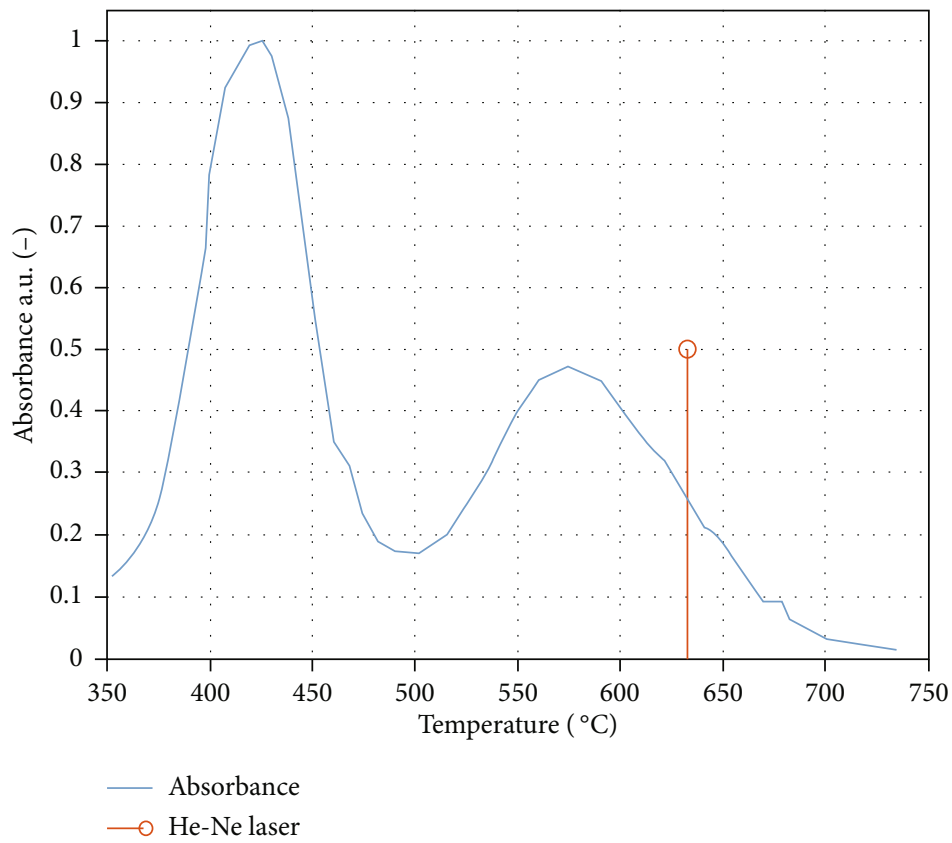

FIgURe 19: Alexandrite absorption spectrum [47].

excitation light. The measured results are shown in Figure 20 $[19,48]$. Fluorescence lifetime at $0^{\circ} \mathrm{C}$ is about $64 \mu$ s and further decreases with an increasing temperature. Cr:LiSAF is usable approximately up to a temperature of about $100^{\circ} \mathrm{C}$. The graph is shown in Figure 21.

Fernicola and Crovini [21] used a Cr:YAG crystal to measure temperatures from -25 to $500^{\circ} \mathrm{C}$. The graph is shown in Figure 22. Their experiment was also based on the measurement of the fluorescence lifetime. For excitation, they used a laser diode with a wavelength of $635 \mathrm{~nm}$, the emission wavelength was $689 \mathrm{~nm}$. They also deployed a quartz fiber with a diameter of $400 \mu \mathrm{m}$. The result of their measurement is shown in Figure 23 [21].
The fluorescence lifetime begins at $35 \mathrm{~ms}$ and decreases with an increasing temperature. The measurement was performed up to a temperature of $500^{\circ} \mathrm{C}$.

A similar measurement with the same material Cr:YAG was performed by Hehir et al. with results in Figure 23 [50]. The temperature range was shifted to lower temperatures from $77 \mathrm{~K}$ to $420 \mathrm{~K}\left(-196 \sim 150^{\circ} \mathrm{C}\right)$.

4.8. Luminescent Material $\mathrm{Nd}^{3+}: Y A G$. Another suitable material for measuring temperature is $\mathrm{Nd}^{3+}: \mathrm{YAG}$. Grattan et al. [60] used a LED diode with a wavelength of $810 \mathrm{~nm}$ for excitation of the $\mathrm{Nd}^{3+}:$ YAG crystal. They used 6 quartz fibers (core diameter $600 \mu \mathrm{m}$ ) for the excitation light and 


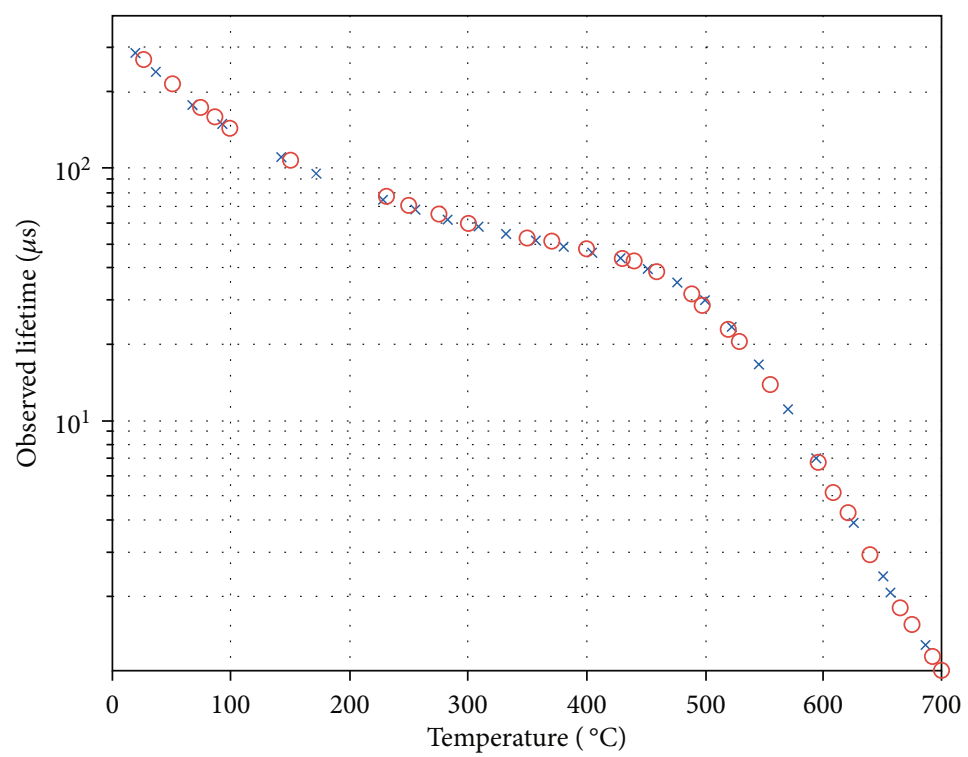

FIGURE 20: Alexandrite fluorescence [19].

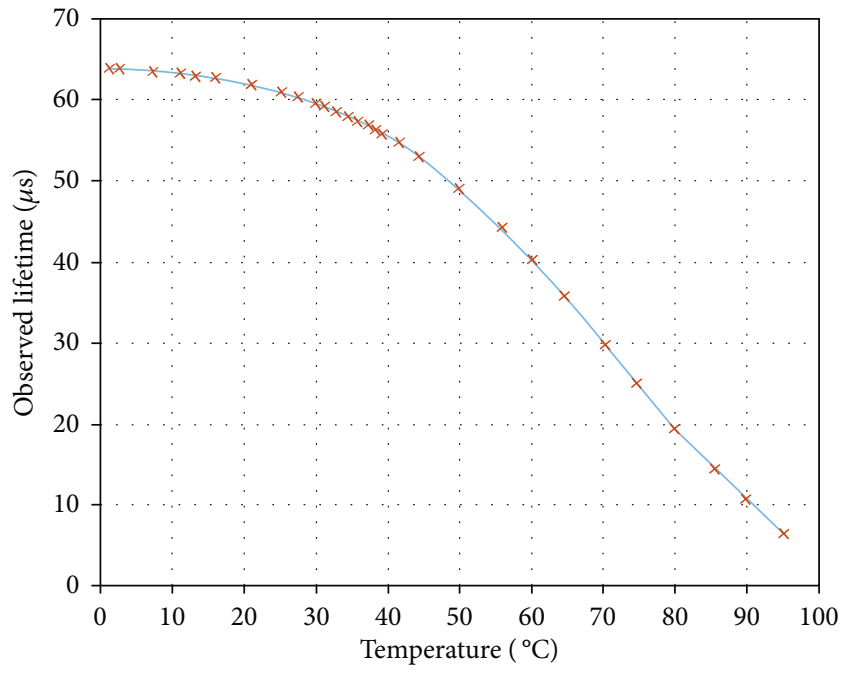

Figure 21: Cr:LiSAF fluorescence [8, 10].

the emission light. The principle of the experiment is again based on the fluorescence lifetime measurement. The lifetime increases with an increasing temperature with a peak of about $700^{\circ} \mathrm{C}$. With a further rise in temperature, the lifetime is decreasing. It is possible to measure temperatures up to about $1000^{\circ} \mathrm{C}$. The measurement results are shown in Figure 24 [19].

4.9. Partial Conclusion for Measurements Using Crystal Materials. The fluorescence lifetime measurement is a more convenient method of measuring the temperature, as the intensity of the emission light can vary greatly. Most commonly, ruby crystals are used. The fluorescence lifetime in ruby is measurable up to approximately $600^{\circ} \mathrm{C}$. The lifetime fluorescence is also affected by the concentration of chromium in ruby and the dimensions of the crystal. The rec- ommended concentration is about $\sim 0.3$ wt.\%. Crystal dimensions should be as small as possible to avoid reabsorption and excitation, which prolongs the fluorescence lifetime. Either red or green lasers are often used for exciting ruby.

Other materials capable of measuring the temperature are alexandrite, Cr:LiSAF, Cr:YAG, or $\mathrm{Nd}^{3+}: Y A G$. For all measurements with these materials, a method of measuring the fluorescence lifetime was used. Alexandrite is able to react to temperatures up to $700^{\circ} \mathrm{C}$. The initial lifetime is 10 times lower than the initial fluorescence lifetime in ruby. Cr:LiSAF is usable up to relatively low temperatures of around $100^{\circ} \mathrm{C}$. It is applied primarily in medical applications. Cr:YAG is usable up to temperatures of around $500^{\circ} \mathrm{C}$; the initial lifetime is long. $\mathrm{Nd}^{3+}$ :YAG is usable at temperatures up to about $1000^{\circ} \mathrm{C}$, but the problem may be an increase in the lifetime with an increasing temperature, a peak of about $700^{\circ} \mathrm{C}$ and a subsequent drop.

Chen et al. and Wu et al. [61, 62] show the possibilities of measuring temperatures on the basis of luminescence using doped ceramic glass. Another contribution is about the sensitivity of temperature measurement using crystalline materials [63]. The construction of a measuring chain for measuring temperature using a fluorescent material is shown in the article "Small and Practical Optical Fiber Fluorescence Temperature Sensor" [22]. The article writes about a practical use of phosphorus for temperature measurement on the principle of extinction time of light luminescence. A scanning probe with a diameter of $1.8 \mathrm{~mm}$ was designed for the described measurement. The paper describes the measurement of temperatures using the time luminescence method, but only up to $90^{\circ} \mathrm{C}$. The results of the described experimental measurement show that the measurement error can reach $0.4^{\circ} \mathrm{C}$ in the measured range of $0-90^{\circ} \mathrm{C}$. Three types of fluorescence sensitive materials were selected for this experiment are described in the article. These are zinc-doped $\mathrm{Mn}^{2+}$ sulfide $\left(\mathrm{ZnS}: \mathrm{Mn}^{2+}\right), \mathrm{Eu}^{3+}$-doped yttrium oxide $\left(\mathrm{Y}_{2} \mathrm{O}_{3}: \mathrm{Eu}^{3+}\right)$, 


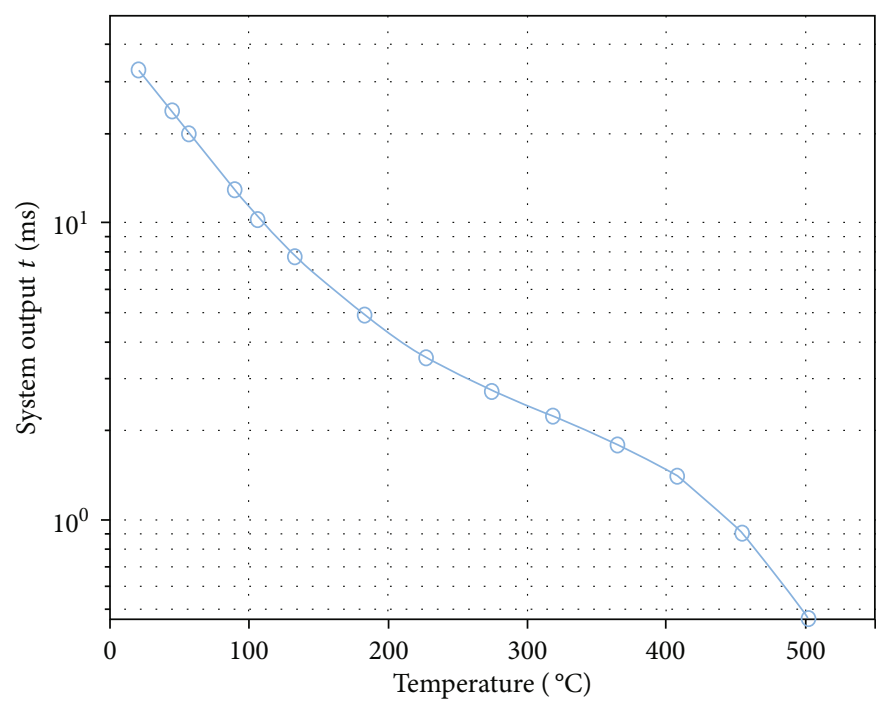

FIGURE 22: Cr:YAG fluorescence lifetime [21].

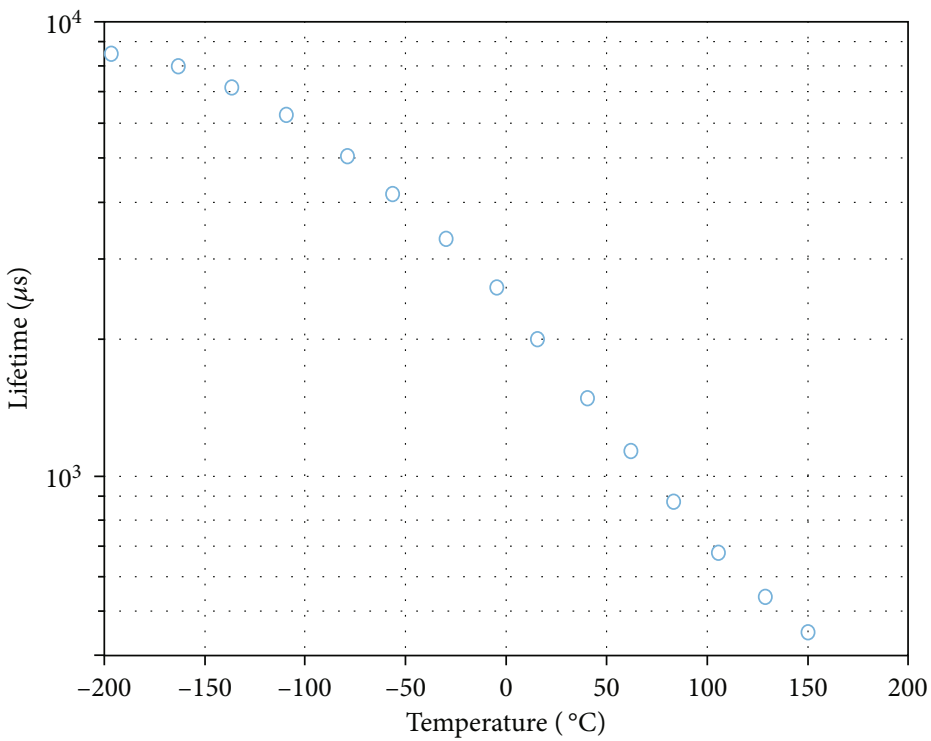

Figure 23: Fluorescence lifetime cycle Cr:YAG [50].

and $\mathrm{Mn}^{4+}$-doped oxyfluoride germanate. Another experiment published in the article "Low Temperature Measurement Using Fluorescence Thermometry" [64] shows a practical measurement and presents a luminescence measurement for measuring negative temperatures. A chromedoped sapphire crystal (ruby) was used as the luminescent material. In the studied cases, the issue of the optical temperature measurement was, except for the practical examples of temperature sensors, mostly only the laboratory use of such an optical temperature sensor.

\section{Measurement Using Fiber Bragg Gratings}

Fiber Bragg gratings (FBGs) are formed in optical fibers by changes in the core refractive index. These are periodic or quasiperiodic changes in the refractive index of the optical fiber. These changes must meet the Bragg condition when the period of change in the core refractive index is equal to half wavelength or its whole multiples (long period). To ensure high efficiency, a sufficient difference between fraction indices and the core structure length is required. If a broadscale light spectrum is fed to the FBG, the central wavelength of the FBG is reflected back and the remaining light passes through the FBG unchanged. The Bragg wavelength is calculated according to Equation (10), where $\lambda_{b}$ is the Bragg wavelength, $n$ is the refractive index of the core of the optical fiber, and $\Lambda$ is the distance between the individual gratings [65-67]. Figure 25 shows the FBG in the optical fiber core. The advantages of the fiber Bragg gratings include small insertion attenuation, small dimensions, 


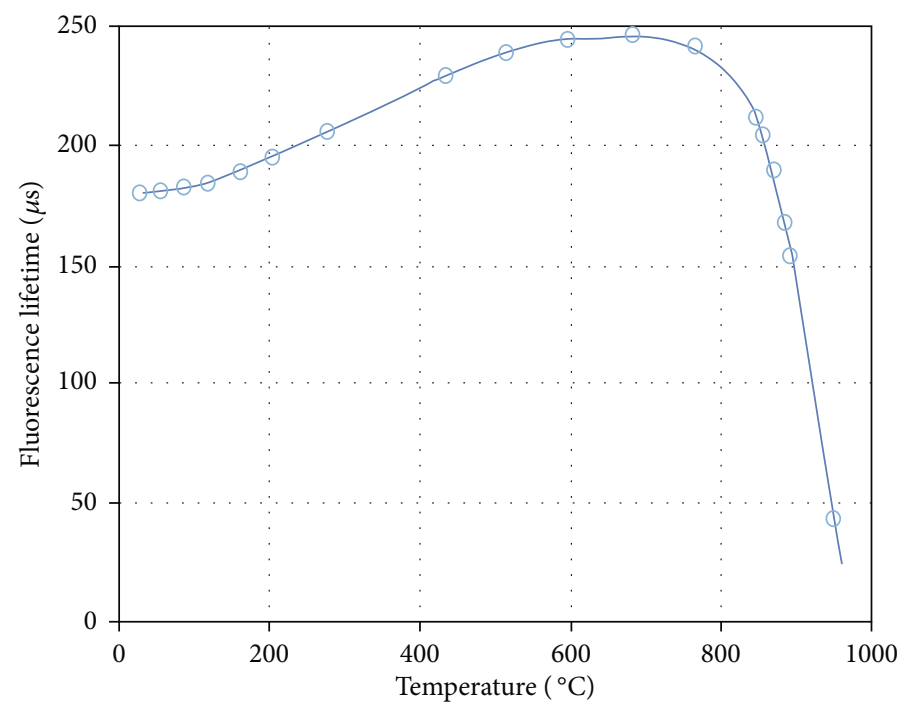

FIGURE 24: $\mathrm{Nd}^{3+}:$ YAG fluorescence [19].

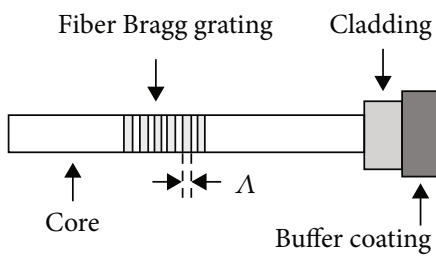

Figure 25: FBG in a fiber [71].

high reliability, and immunity to electromagnetic interference $[28,65,66,68-72]$.

$$
\lambda_{b}=2 n \Lambda
$$

Changes in pressure and temperature affect the refractive index of the distance of the individual gratings, resulting in a change in the reflected wavelength. This can be roughly described by

$$
\frac{\Delta \lambda}{\lambda_{0}}=1-p_{e} \cdot \varepsilon+\left(\alpha_{\Lambda}+\alpha_{n}\right) \cdot \Delta T
$$

where $\Delta \lambda$ is a wavelength change, $\lambda_{0}$ is the initial wavelength, $p_{e}$ is the optical-strain coefficient, and $\varepsilon$ is the strain acting on the FBG. The second part describes the influence of temperature on the wavelength shift, where $\alpha_{\Lambda}$ is the coefficient of thermal expansion, which describes the grid extension due to the temperature; $\alpha_{n}$ is the thermooptical coefficient describing the change of the refractive index; and $\Delta T$ is temperature change in $\mathrm{K}$.

Fiber Bragg gratings are highly suitable for accurate measurements of both low and high temperatures. For very high-temperature ranges, it is necessary to use hightemperature-resistant materials for the production of optical fibers and to choose a durable method for permanent FBG registration. The FBG temperature sensor solution is very simple and compact. The connection consists only of

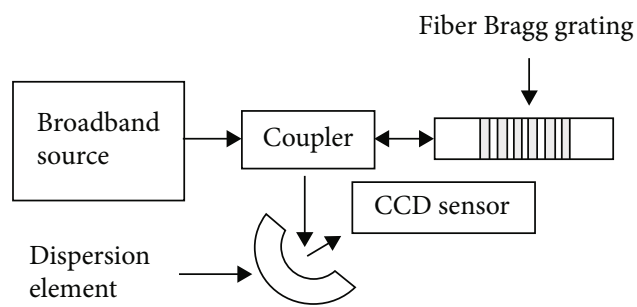

FIGURE 26: FBG connecting the light source and spectrometer to the FBG [75].

an optical source, spectrometer, divider, and the FBG-see Figure 26. With the use of one optical source and spectrometer, a large number of the fiber Bragg gratings can be monitored, but the ranges of individual gratings cannot interfere with each other. The disadvantage of this solution is the thermal stabilization of the light source and the spectrometer [65-70, 73, 74].

The fiber Bragg grating is very sensitive to temperature changes. As the temperature increases, distances between the fiber Bragg gratings are widened, thus moving the central wavelength of the FBG. If it is necessary to increase the sensitivity, the FBG can be combined with a material that has a higher thermal expansion than glass.

5.1. Types of Bragg Gratings. We distinguish three basic types of gratings: Type I, Type II, and regenerated ones. The common type is Type I, which can be formed in many types of a germanium-doped fiber. They are very sensitive to UV light. Low-power UV lamps are used as sources which affect germanium dioxide by side-lighting of the fiber. These methods include interferometric, phase mask, and point-by-point production. These gratings are capable of measuring temperatures up to $320^{\circ} \mathrm{C}$ with a response of $10 \mathrm{pm} /{ }^{\circ} \mathrm{C}$; above this temperature, they are no longer stable and degrade. The radiated part of the core has a higher index than the nonradiated core. In addition, we can use the IH type where germanium is 
replaced by hydrogen that absorbs UV photons or a combination of hydrogen dopants and germanium $\mathrm{IHp}$, where the temperature stability is shifted up to $500^{\circ} \mathrm{C}$ with a response of $7 \mathrm{pm} /{ }^{\circ} \mathrm{C}$. The last type is Id, where changes in the density of the undoped quartz core are induced by the laser (just before damaging the quartz structure) that is created. This type has higher dissipation losses than Type I but lower than Type II. In this type, the temperature stability is in the range of $500-800^{\circ} \mathrm{C}$; the response is $11 \mathrm{pm} /{ }^{\circ} \mathrm{C}$ [76].

Athermal gratings (Type II) can be created using powerful lasers, chemical production, and thermal regeneration. Using a high-power laser, microscopic damage is produced in the core. Due to permanent damage to the core structure without dopants, they have an increased temperature stability of over $1000^{\circ} \mathrm{C}[25]$.

The last type is represented by the regenerated fiber Bragg gratings, which are made by annealing of the first type gratings (at temperatures above $1000^{\circ} \mathrm{C}$ ). This makes it possible to obtain gratings with extreme stability without further degradation but at the expense of low reflectivity.

The FBG can be created on a conventional SMF using a femtosecond laser. However, this structure is stable up to $1050^{\circ} \mathrm{C}$, after exceeding this value, the grating is irreversibly transmitted. In this method, the fiber is markedly stressed by the temperature, and reliability and geometry are affected.

Another type is a femtosecond pulse of Type II where residual stress is released due to long annealing, thus achieving the stability up to $1200^{\circ} \mathrm{C}$. However, the fiber is fragile after several hours of annealing, which limits the range of its application.

Other improvements came with the use of rapid air cooling when the FBG is created using a femtosecond laser, and consequently, the fiber is quickly cooled by cold air. This will stabilize the grating up to $1200^{\circ} \mathrm{C}$ while increasing its mechanical resistance. The grating remains unchanged for a minimum of 26 hours at $1200^{\circ} \mathrm{C}$ [23].

The fiber Bragg gratings that are resistant even above $1500^{\circ} \mathrm{C}$ can be produced using sapphire fibers. The structure is written into these fibers by means of the femtosecond laser. The sapphire fiber is multimode; therefore, it has a larger reflecting bandwidth compared to the FBG in SMF [77, 78].

Another option is the production of the FBG using a $193 \mathrm{~nm}$ ArF laser into a preheated germanium-doped quartz fiber [25].

5.2. Partial Conclusion for Measurement Methods Using the Fiber Bragg Gratings. There are several ways of measuring using the fiber Bragg gratings; the main advantage is always the resistance to magnetic and electrical interference. Compared to the optical methods described above, the FBG can be used not only for temperature measurements but also for measuring deformations and torques [28]. These methods can also be used in the biomedical area, for example, $[26,27]$ provide possibilities for monitoring the basic human functions. The article by Matveenko et al. [28] deals with the implementation of measurements in plastic materials. There is a disadvantage in some measurement applications, because of the narrow-spectrum laser source that should be thermally compensated. This disadvantage can be overcome by using wider spectrum sources, where the magnitude of the spectral shift of light reflected by the FBG is usually evaluated. Another disadvantage of the FBG is the inability to use it for high temperatures, with a higher measuring range requiring other types of gratings; lower accuracy is achieved, or the cost of these gratings increases. As standard, the FBGs are used approximately to measure temperatures up to $320^{\circ} \mathrm{C}$. In special cases, resistance can be achieved up to $1500^{\circ} \mathrm{C}$.

\section{Interferometric Temperature Sensors}

These interferometric methods measure phase shift between two coherent beams that have travelled the same path in one or two optical fibers. In conditions when the length of both arms and their refractive index of the core is the same or in multiples of wavelengths $2 \pi \mathrm{rad}$, the resulting interference is constructive and the output of the interferometer is at a maximum. If the difference is in odd multiples of the wavelengths $(2 m-1) \pi \mathrm{rad}$, the output is at a minimum. In the case of a general double-arm interferometer, the phase response increases linearly with arm length.

Interferometers are able to detect 3 mechanisms that affect the optical beam: change in path length, wavelength, and change in the speed of light propagation (refractive index).

A change in any of these quantities will result in a change in the phase of the wave. This depends on the path length $L$, the refractive index $n$, and the working wavelength $\lambda$. The phase delay of the light is given by

$$
\Phi=2 \pi n\left(\frac{L}{\lambda}\right) .
$$

To measure the temperature, it is necessary to know information about the current value of the phase delay and wavelength shift. So, we need information about the amplitude and spectrum.

The design of interferometers for temperature measurement can use different types of interferometers. A review article on interferometers is presented by Lee et al. [30] where the possibilities and uses of different types of fiber optic sensors were summarized.

6.1. Mach-Zehnder Interferometer (MZI). Various types of fiber in-line MZI structures have been developed, such as tapered fiber structures in single-mode fibers $[29,79,80]$.

The in-line Mach-Zehnder interferometer is shown in Figure 27.

Other MZI can be based on inner air microcavity $[81,82]$ and core-offset structures $[83,84]$. The mentioned MZI are based on the difference of the effective refractive index between the core and cladding, so the temperature sensitivity is relatively low. A solution can be the use of graded index fibers as a collimator, which can achieve spectral temperature sensitivity around $12.37 \mathrm{~nm} /{ }^{\circ} \mathrm{C}$ [85]. Even some hybrid solutions can be found $[86,87]$. 


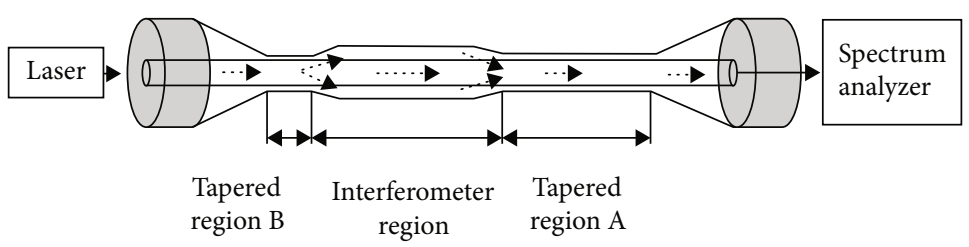

Figure 27: In-line Mach-Zehnder interferometer [79].

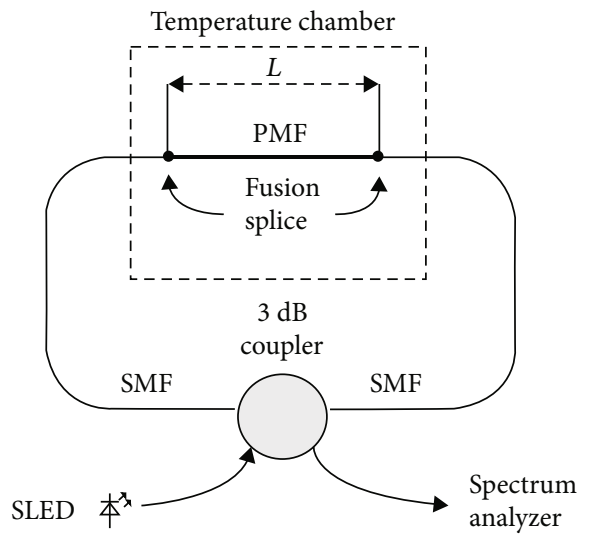

FIGURE 28: Sagnac interferometer for temperature measurement [93].

With cascade connection of MZI, the temperature response of each MZI was $0.063 \mathrm{~nm} /{ }^{\circ} \mathrm{C}$ from $30^{\circ} \mathrm{C}$ to $1000^{\circ} \mathrm{C}, 0.071 \mathrm{~nm} /{ }^{\circ} \mathrm{C}$ from $30^{\circ} \mathrm{C}$ to $500^{\circ} \mathrm{C}$, and $0.059 \mathrm{~nm} /{ }^{\circ} \mathrm{C}$ from $30^{\circ} \mathrm{C}$ to $1000^{\circ} \mathrm{C}[31]$.

6.2. Michelson Interferometer. The Michelson interferometer comes up with the possibility of a single-ended measurement probe, so we can measure temperature at the end of the fiber [88-90]. Other configurations can employ a high birefringence fiber [91]. An advantage is that it is possible to make this interferometer easily with an ordinary optical fiber and splicer. And since silica fiber can sustain high temperatures, there is a possibility to measure in high temperatures. The maximum temperature sensitivity of $115.34 \mathrm{pm} /{ }^{\circ} \mathrm{C}$ at $550^{\circ} \mathrm{C}$ was achieved [92].

6.3. Sagnac Interferometer. This method of measurement compares two light waves that are transmitted against each other $[93,94]$. If the frequencies of electromagnetic waves are different, the phase shift between them is changing with the time. As a result, we can detect interferences (periodic changes at minimum and maximum).

A schematic of this type of measurement is shown in Figure 28.

The light is emitted from SLED and goes through a $3 \mathrm{~dB}$ optocoupler. Single-mode optical fibers transfer light to the measurement part with a polarization maintaining fiber. As a result, we can measure the shift of the interference spectrum of the PMF. The sensitivity of $1.38 \mathrm{~nm} /{ }^{\circ} \mathrm{C}$ was achieved within the temperature range $21-50^{\circ} \mathrm{C}$ [93] or even $18.27 \mathrm{~nm} /{ }^{\circ} \mathrm{C}$ within the range $0-40^{\circ} \mathrm{C}$ [95]. However, a wide spectrum of research around this type of temperature measurement seems to be limited to temperatures of around $120^{\circ} \mathrm{C}$ [96]. The main reason for such limitation is the periodic nature of this measurement, also mentioned by Domínguez-Cruz et al. [97] or Cui et al. [98]. Figure 29 shows that measured waveforms have more than one spike, so we cannot perform measurements outside this limit.

As a result, the Sagnac interferometer is more suitable for a close range of temperatures, while offering high sensitivity. The only possibilities are decreasing the sensitivity or making the periodic effect in the waveform wider.

6.4. Modal Interferometer. This method is based on the reflective single-mode-multimode-single-mode fiber structure. The measurement is achieved via monitoring the spectral shift of the modal interference between the core and the cladding modes in the ended single-mode fiber. The achieved sensitivity was $-92.6 \mathrm{pm} /{ }^{\circ} \mathrm{C}$ in the range of 28 to $51^{\circ} \mathrm{C}$ [99].

Another type is a fiber optic modal interferometer fabricated by a segment of a low elliptical hollow-core photonic bandgap fiber (EHC-PBGF), where $12.99 \mathrm{pm} /{ }^{\circ} \mathrm{C}$ was achieved within the range from 30 to $110^{\circ} \mathrm{C}[100]$.

With regard to high-temperature measurements, we can mention a thin-core fiber (TCF) modal interferometer for temperatures up to $850^{\circ} \mathrm{C}$ with $18.3 \mathrm{pm} /{ }^{\circ} \mathrm{C}$ sensitivity [101].

Figure 30 shows a schematic of a thin-core modal interferometer, where the thin-core fiber is placed between two standard single-mode fibers (SMF).

Another high-temperature modal interferometer is based on a hollow-core fiber (HCF) where temperatures up to $1000^{\circ} \mathrm{C}$ were achieved with sensitivity up to $33.4 \mathrm{pm} /{ }^{\circ} \mathrm{C}$ [32].

6.5. Fabry-Perrot Interferometer. Figure 31 shows a hybridstructured Fabry-Perot interferometer (HSFPI) based on large lateral offset splicing for simultaneous measurement of the strain and temperature. An advantage of this structure is price and easy fabrication; however, spectrum measurement is not always convenient for real low-cost deployment. In this case, sensitivity of $12.71 \mathrm{pm} /{ }^{\circ} \mathrm{C}$ was achieved within the temperature range of $100-700^{\circ} \mathrm{C}$ [102].

In articles from Wang et al. [103-105], the proposals of intrinsic and extrinsic fiber optic sensors based on the Fabry-Perot interferometer were able to measure up to $1600^{\circ} \mathrm{C}$.

A proposal of a fiber optic Fabry-Perot interferometric (FFPI) sensor by using PFC (photonic crystal fiber) as a high-temperature sensor was achieved by Ding et al. [33]. The measurement shows that sensitivity of $10 \mathrm{pm} /{ }^{\circ} \mathrm{C}$ can be achieved together with the temperature range over $1200^{\circ} \mathrm{C}$. 


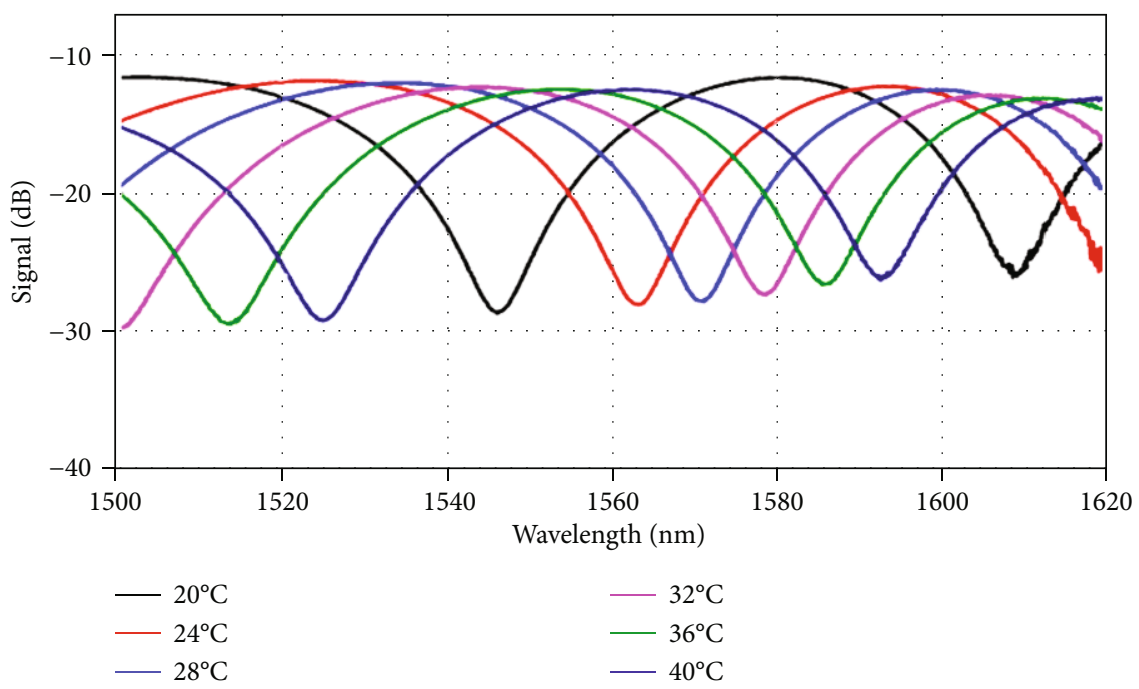

Figure 29: Temperature and spectrum measurement for Sagnac interferometer [97].

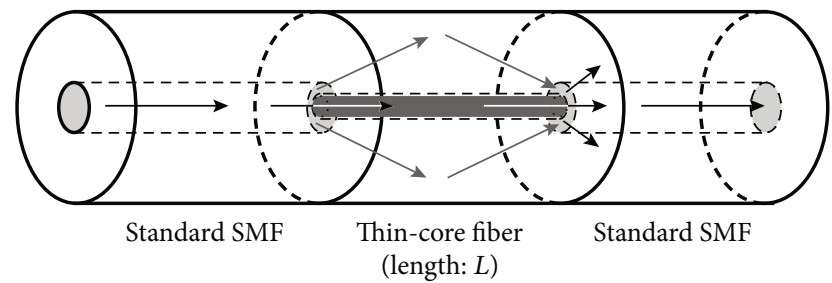

Figure 30: Thin-core fiber interferometer scheme [101].

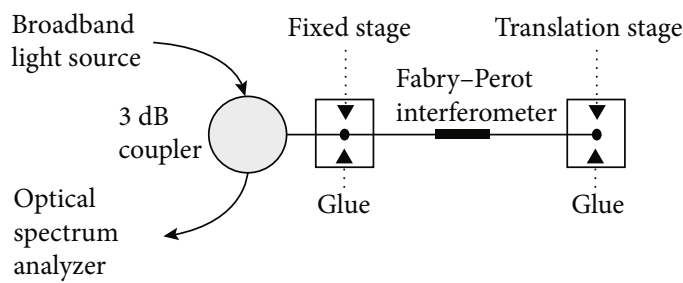

Figure 31: Fabry-Perrot interferometer setup [102].
6.6. Partial Conclusion for the Interferometric Measurement Methods. Interferometric sensors are capable of measuring high temperatures, especially with the Mach-Zehnder or Fabry-Perrot configurations. Physical limitations are given by optical fiber endurance, so there is also possibility to measure with special fibers up to $1600^{\circ} \mathrm{C}$. There are also lowtemperature configurations like the Sagnac interferometer which can offer much higher resolution. The resolution reaches values $18.27 \mathrm{~nm} /{ }^{\circ} \mathrm{C}$ [95] in comparison with only $10 \mathrm{pm} /{ }^{\circ} \mathrm{C}$ for the Fabry-Perrot interferometer [33]. So the measurement is more precise, but the temperature range is low. A compromise between range and sensitivity is offered by MZI or Michelson.

However, interferometric measurements can also be quite sensitive to ambient vibrations or other mechanical changes.

\section{Real Deployment and the Future}

Nowadays, some manufacturers already started to focus on fiber-based sensors. Optical sensors can be specially designed to allow measurements in extreme environments including automotive [106], where temperature of the brake and the clutch can be measured in the $200-1200^{\circ} \mathrm{C}$ range. The advantage of this measurement is that we do not need information about low temperatures, so the blackbody measurement and IR sensor can be used. Another type of sensor is specified by the manufacturer
Anton Paar [107]. This type of optical temperature sensor uses the principle of measuring with a ruby crystal. The sensor uses the principle described in the chapter on luminescence measurement. The principle of the measurement is based on measuring the temperature-dependent decay time of the ruby crystal luminescence. The sensor manufacturer provides information on temperature measurements up to $300^{\circ} \mathrm{C}$. Advantages of this sensor are the calibration-free design and low-temperature measurement, which is not possible with blackbody. And a nonmetallic design also meets immunity for use in electromagnetic interference environments.

The future of every method is connected to its low-cost version. So the spectrum-based sensors have a major disadvantage even if they cover the required temperature range. However, there is possibility to combine individual optical methods that are cheaper but usually suitable only for measuring a narrow temperature range. Figure 32 shows the possible combination of luminescence and blackbody measurement. A suitable luminescent material can survive high temperatures during blackbody measurement together with the measurement possibility at low temperatures. Accuracy of the amplitude-based measurement could be affected during the manufacturing, so any optical sensor constructed in this manner will require calibration before being used for measuring temperatures. But the detection part of the system could be a simple photodetector, so it is still an interesting way. 


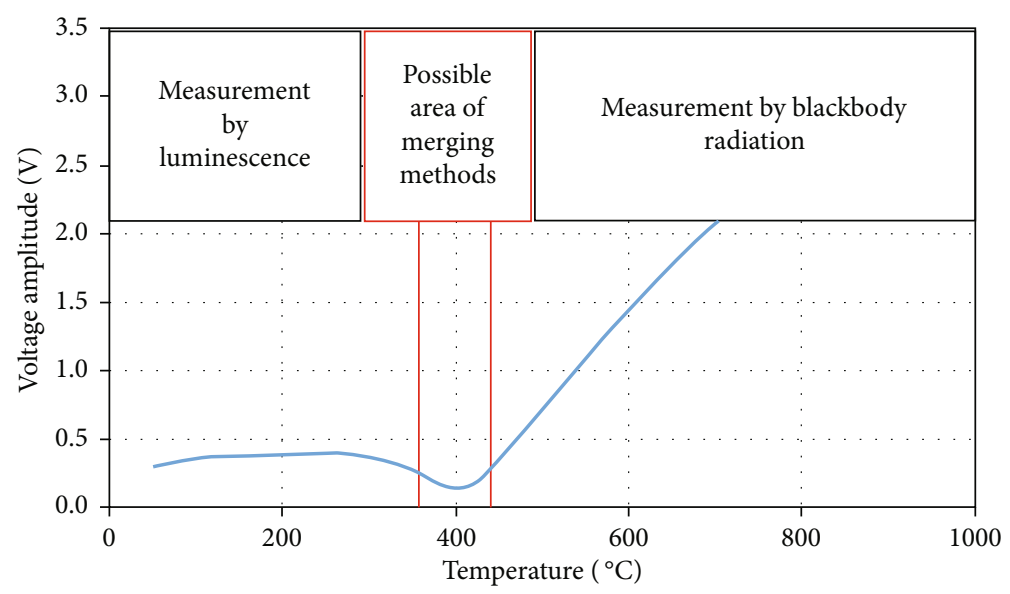

FIGURE 32: Expected signal from the photodetector using a combination of optical methods.

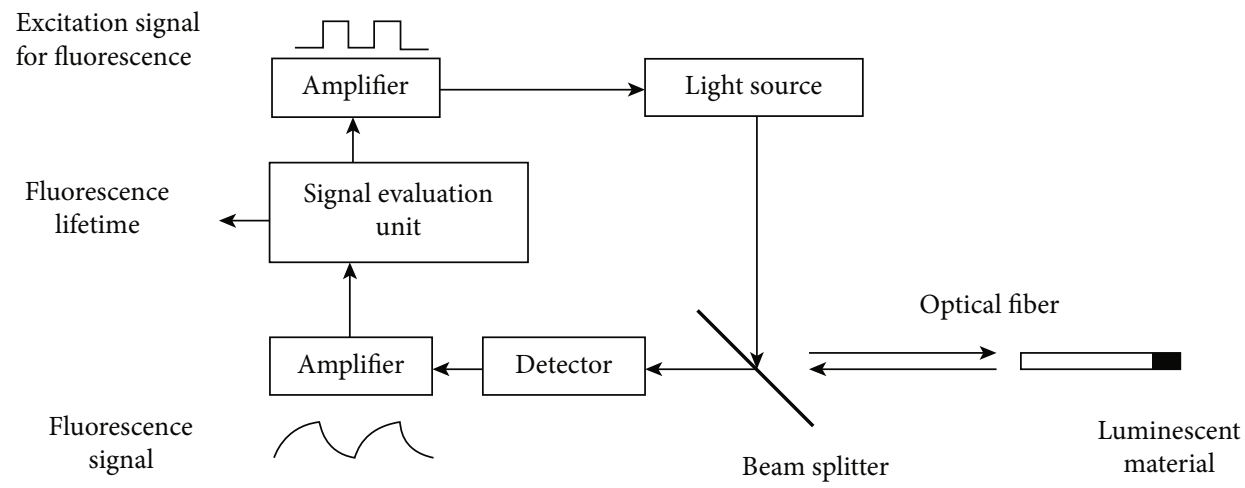

FIGURE 33: A temperature measurement system for combination of measuring methods [108].

The principle of possible connection for this method by a combination of measuring methods can be performed according to Figure 33. This method of optical connection is also mentioned in the article "Temperature Monitoring System of Electric Apparatus Based On Optical Fiber Fluorescence" [108]. It can be assumed that such a sensor allows measurements from low temperatures (use of luminescence) to temperatures around $1000^{\circ} \mathrm{C}$ (use of blackbody radiation). This type of sensor finds application in many industrial areas in which it is necessary to resist electromagnetic interference and galvanic separation of the thermometer from the measured object for measuring high temperatures, for example, in the field of metal welding.

\section{Discussion and Summary of the Pitfalls of the Individual Optical Measuring Methods Described}

Several methods of temperature measurement based on optical measurement methods were presented in this article. If fiber Bragg gratings are used, this method can also be applied to measure deformations, bends, or vibrations. Generally, each method has its own pitfalls. At present, the problem of temperature measurement for most applications can be solved using the mastered and calibrated methodology using resistance or thermocouple methods. The purpose of this article was not to determine a method that would replace a specific temperature measurement using a nonelectric fiber optic probe in cases where electrical measuring probes can be unreliable due to the effects of electrical and magnetic interference. The answer to this question cannot be easily obtained. This is mainly because each system requires specific temperature ranges, the dynamics of the measuring system, the working environment, the impact of vibrations, and so on. However, the following findings can be summarized from this article. The blackbody- (greybody-) based method is suitable for temperatures operating from $500^{\circ} \mathrm{C}$ to $2000^{\circ} \mathrm{C}$ using commonly available optical fibers. In terms of mechanical design, this method appears to be the most robust one, mainly due to the fact that only the end of the glass fiber with the blackbody is brought into the measured area. This method is suitable for the use in measurement areas for measuring temperatures of $500^{\circ} \mathrm{C}$ and above, for simplicity; a rapid response of the measuring system can be achieved because of the good dynamics of changing the temperature of the blackbody negligible mass. However, when designing a measuring system, it is always necessary to consider the instability of this measuring chain when changing the temperature on the part of the evaluation side and the photodetector. Therefore, it is necessary to place a high emphasis on the temperature stability of the evaluation electronics or to 
consider these temperature changes of the photodetector and the evaluation unit when evaluating the received light power at the conversion to the measured temperature. In cases where we would like to apply the measurement methods using crystal luminescence, it is also necessary to consider the need for thermal compensation of the photodetector when evaluating the received light output. Moreover, in cases where this method is used in a real measuring chain, it is also necessary to know its temperature due to the nonlinearity of the excitation light source and to include it in the overall result evaluation. For the luminescent measurement method, the correct crystal must be selected for the measured temperature range. The dynamics of the measuring system will also depend on the size of the crystal used and the type and size of the protective shield. The method always requires an external excitation, for example, with a photodiode. The individual measuring ranges are listed in the article, and they always depend on the excitation light and crystal used. Using this crystal method, the basic advantage is the possibility to perform measurements in the temperature range $0-400^{\circ} \mathrm{C}$. However, the disadvantage may be the need to use a crystal and to establish a mechanical and optical connection between the fiber and the crystal; in this case, a nonlinear transmission of optical power between the individual parts may occur due to mechanical and thermal instability. The method of the fiber Bragg gratings also provides an alternative to measuring temperatures in lower temperature ranges. When using this method, it is also necessary to take into account the temperature calibration and compensation for the excitation source and photodetector. We have a choice of several types of gratings described in this article to realize the thermal or mechanical measurements using this method. The method is particularly suitable for lower measuring ranges of up to $320^{\circ} \mathrm{C}$ when we achieve the required accuracy of about $10 \mathrm{pm} /{ }^{\circ} \mathrm{C}$. For higher temperatures, the special and more expensive gratings mentioned in this article are used. The last mentioned methods are interferometric measurements. The achieved temperature range depends on the chosen configuration, and it is able to cover temperatures over $1200^{\circ} \mathrm{C}$. However, interferometric measurement is able to interact with mechanical changes in the system, especially vibrations. Signal measurement also requires spectrum analysis, which creates an expensive part of the system. As a result, we can achieve fiber optic measurement in wide range of temperatures but with the limitation of sensitivity to mechanical interferences (also depends on configuration). It is possible to implement this type of measurement in laboratory conditions, but its implementation in harsh industrial environments can be difficult.

\section{Conclusion}

This article contains information and partial evaluation of various optical fiber methods in temperature measurement. It is advisable to consider measurements using optical methods in cases where the electrical and magnetic interference can be taken into account in the temperature measuring range or in cases where we need to remove the galvanic connection between the measured object and the evaluation unit.
For example, optical methods can measure the temperature of electrical wires used for high-voltage and microwave applications. The article describes individual optical principles and presents the benefits and applicability of the methods mentioned. When designing the measuring chain, it is always necessary to take into account the dynamic range, the sensitivity, and the resistance to mechanical and electrical influences. It is also important to recall the necessary thermal compensation of optical receivers and transmitters in cases where it would be decided to replace the existing purely electrical modes of temperature measurement by optical methods. These optical semiconductor transmitters and receivers are usually more temperature dependent than those used to process the signal from thermocouples and resistive temperature sensors. However, in designing the temperature measuring chain using these optical methods, in addition to removing the effect of the above-mentioned magnetic interference, a long nonelectrical connection between the measured point and the evaluation unit is obtained. Designing such a measurement system is always a compromise between the price and utility value of such a system and choosing the appropriate method with the individual options described in this article.

\section{Data Availability}

No data used to support the findings of this study.

\section{Conflicts of Interest}

There is no conflict of interest.

\section{Acknowledgments}

This work was supported by the MPO Trio in the Research and Development of Optical and Fiber-Optical Temperature Sensors for Automotive Applications Project (project number FV10422). This work was supported by the European Regional Development Fund in the Research Centre of Advanced Mechatronic Systems project, project number CZ.02.1.01/0.0/0.0/16_019/0000867 within the Operational Programme Research, Development and Education.

\section{References}

[1] W. J. Bock, M. S. Nawrocka, W. Urbanczyk, J. Rostkowski, and T. Martynkien, "Fiber-optic sensor for automotive applications," in Proceedings of IEEE Sensors, 2004, pp. 248-251, Vienna, Austria, 2004.

[2] J. Jiang, S. Wang, K. Liu et al., "Development of optical fiber temperature sensor for aviation industry," in 2016 15th International Conference on Optical Communications and Networks (ICOCN), pp. 1-3, Hangzhou, China, 2016.

[3] D. M. Scott, Industrial Process Sensors, CRC Press, Boca Raton, FL, USA, 2008.

[4] T. J. Moore, M. R. Jones, D. R. Tree, and D. D. Allred, "An inexpensive high-temperature optical fiber thermometer," Journal of Quantitative Spectroscopy and Radiative Transfer, vol. 187, pp. 358-363, 2017. 
[5] O. S. Gefle and M. S. Lebedev, "Diagnostic of pre-breakdown state of polymeric insulators by the thermovision method," in 2007 IEEE International Conference on Solid Dielectrics, pp. 647-650, Winchester, UK, 2007.

[6] T. Macrea, D. Macrea, and C. Cepisca, "Thermovision lubrication monitoring system for a mechanical expander," in 2011 7TH International Symposium on Advanced Topics in Electrical Engineering (ATEE), pp. 1-4, Bucharest, Romania, 2011.

[7] M. Smiko, M. Chupac, and M. Gutten, "Thermovision measurements on electric machines," in 2018 International Conference on Diagnostics in Electrical Engineering (Diagnostika), pp. 1-4, Pilsen, Czech Republic, 2018.

[8] M. Sebok, M. Kucera, M. Gutten, T. Koltunowicz, and P. Zukowski, "Thermovision measurement and diagnostics of electrical machines," in 2019 12th International Conference on Measurement, pp. 299-302, Smolenice, Slovakia, 2019.

[9] H. Ogura, H. Numajiri, and T. Kobayashi, "Study on the reliability of comparison method for thermocouples in industry around $1324^{\circ} \mathrm{C}$," in SICE Annual Conference 2011, pp. 451453, Tokyo, Japan, 2011.

[10] M. Zhu, "A universal smart temperature sensor for thermocouples," in 2014 IEEE International Conference on Information and Automation (ICIA), pp. 852-855, Hailar, China, 2014.

[11] S. Donati, Photodetectors: Devices, Circuits and Applications, Prentice-Hall, Upper Saddle River, NJ, USA, 2000.

[12] S. Hanacek, J. Latal, P. Siska et al., "Fibre optic sensor for high temperatures," Advances in Electrical and Electronic Engineering, vol. 8, pp. 6-9, 2010.

[13] M. R. Jones and D. G. Barker, "Use of blackbody optical fiber thermometers in high-temperature environments," Journal of Thermophysics and Heat Transfer, vol. 16, no. 3, pp. 306312, 2002.

[14] Y.-B. Yu and W. K. Chow, "Review on an advanced hightemperature measurement technology: the optical Fiber thermometry," Journal of Thermodynamics, vol. 2009, Article ID 823482, 11 pages, 2009.

[15] H. C. Seat, J. H. Sharp, Z. Y. Zhang, and K. T. V. Grattan, "Single-crystal ruby fiber temperature sensor," Sensors and Actuators A: Physical, vol. 101, no. 1-2, pp. 24-29, 2002.

[16] Y. L. Hu, Z. Y. Zhang, K. T. V. Grattan, A. W. Palmer, and B. T. Meggitt, "Ruby-based decay-time thermometry: effect of probe size on extended measurement range (77-800 K)," Sensors and Actuators A: Physical, vol. 63, no. 2, pp. 85-90, 1997.

[17] K. T. V. Grattan, R. K. Selli, and A. W. Palmer, "Ruby decaytime fluorescence thermometer in a fiber-optic configuration," Review of Scientific Instruments, vol. 59, no. 8, pp. 1328-1335, 1988.

[18] H. C. Seat and J. H. Sharp, "Dedicated temperature sensing with $\mathrm{c}$-axis oriented single-crystal ruby $(\mathrm{Cr} / \mathrm{sup} 3+\mathrm{Al} / \mathrm{sub}$ 2/O/sub 3/) fibers: temperature and strain dependences of R-line fluorescence," IEEE Transactions on Instrumentation and Measurement, vol. 53, no. 1, pp. 140-154, 2004.

[19] K. T. V. Gratten and B. T. Meggitt, Optical Fiber Sensor Technology-Volume 3: Applications and Systems (Optoelectronics, Imaging and Sensing), Springer, 1999.

[20] K. T. V. Grattan, R. K. Selli, and A. W. Palmer, "Ruby fluorescence wavelength division fiber-optic temperature sensor," Review of Scientific Instruments, vol. 58, no. 7, pp. 12311234, 1987.
[21] V. Fernicola and L. Crovini, "Digital optical fiber point sensor for high-temperature measurement," Journal of Lightwave Technology, vol. 13, no. 7, pp. 1331-1334, 1995.

[22] Y. Zhao, M.-Q. Chen, R.-Q. Lv, P. Wang, and X. Feng, "Small and practical optical fiber fluorescence temperature sensor," IEEE Transactions on Instrumentation and Measurement, vol. 65, no. 10, pp. 2406-2411, 2016.

[23] Y. Li, M. Yang, C. Liao, D. Wang, J. Lu, and P. Lu, "Prestressed fiber Bragg grating with high temperature stability," Journal of Lightwave Technology, vol. 29, no. 10, pp. 15551559, 2011.

[24] J. Canning, S. Bandyopadhyay, M. Stevenson, and K. Cook, "Fiber Bragg grating sensor for high temperature application," in OECC/ACOFT 2008 - Joint Conference of the OptoElectronics and Communications Conference and the Australian Conference on Optical Fibre Technology, pp. 1-2, Sydney, Australia, 2008.

[25] S. Alqarni, M. Bernier, and C. Smelser, "Annealing of high temperature stable hydrogen loaded fiber Bragg gratings," IEEE Photonics Technology Letters, vol. 28, no. 9, pp. 939942, 2016.

[26] M. Fajkus, J. Nedoma, R. Martinek, V. Vasinek, H. Nazeran, and P. Siska, "A non-invasive multichannel hybrid fiberoptic sensor system for vital sign monitoring," Sensors, vol. 17, no. 12, p. 111, 2017.

[27] J. Nedoma, M. Fajkus, R. Martinek, and V. Vasinek, "Noninvasive fiber-optic biomedical sensor for basic vital sign monitoring," Advances in Electrical and Electronic Engineering, vol. 15, no. 2, 2017.

[28] V. P. Matveenko, I. N. Shardakov, A. A. Voronkov et al., "Measurement of strains by optical fiber Bragg grating sensors embedded into polymer composite material," Structural Control and Health Monitoring, vol. 25, no. 3, article e2118, 2018.

[29] P. Lu, L. Men, K. Sooley, and Q. Chen, “Tapered fiber MachZehnder interferometer for simultaneous measurement of refractive index and temperature," Applied Physics Letters, vol. 94, no. 13, article 131110, 2009.

[30] B. H. Lee, Y. H. Kim, K. S. Park et al., "Interferometric fiber optic sensors," Sensors, vol. 12, no. 3, pp. 2467-2486, 2012.

[31] N. Zhao, Q. Lin, Z. Jiang et al., "High temperature high sensitivity multipoint sensing system based on three cascade Mach-Zehnder interferometers," Sensors, vol. 18, no. 8, p. $2688,2018$.

[32] D. Liu, Q. Wu, C. Mei et al., "Hollow core fiber based interferometer for high-temperature $\left(1000^{\circ} \mathrm{C}\right)$ measurement," Journal of Lightwave Technology, vol. 36, no. 9, pp. 1583-1590, 2018.

[33] W. Ding, Y. Jiang, R. Gao, and Y. Liu, "High-temperature fiber-optic Fabry-Perot interferometric sensors," Review of Scientific Instruments, vol. 86, no. 5, article 055001, 2015.

[34] A. Othonos and K. Kalli, Fiber Bragg Gratings: Fundamentals and Applications in Telecommunications and Sensing, Artech House, Boston, MA, USA, 1999.

[35] A. Cusano, A. Cutolo, and J. Albert, Fibre Bragg Grating Sensors: Recent Advancements, Industrial Applications and Market Exploitation, Betham Science,, 2nd edition, 2018.

[36] Y.-q. Yao, W.-1. Liang, X. Gui, and D. Fan, "Sapphire FabryPerot high-temperature sensor study," in 25th International Conference on Optical Fiber Sensors, pp. 4-23, Jeju, Republic of Korea, 2017. 
[37] J. Wang, E. M. Lally, B. Dong, J. Gong, and A. Wang, "Fabrication of a miniaturized thin-film temperature sensor on a sapphire fiber tip," IEEE Sensors Journal, vol. 11, no. 12, pp. 3406-3408, 2011.

[38] V. A. Zakharchcnko, Y. R. Veprikova, and D. Y. Kropachev, "Substantiation of parametric method of melt temperature measurement," in 2018 XIV International ScientificTechnical Conference on Actual Problems of Electronics Instrument Engineering (APEIE), pp. 111-115, Novosibirsk, Russia, 2018.

[39] ThorlabsSeptember 2019, https://www.thorlabs.com/ newgrouppage9.cfm?objectgroup_id=7062\#ad-image-0.

[40] W. Wei, S. Xiaotian, and W. Ying, "Sapphire fiber-optic temperature sensor based on black-body radiation law," Procedia Engineering, vol. 99, pp. 1179-1184, 2015.

[41] X. Zhou, X. Meng, A. B. Krysa, J. R. Willmott, J. S. Ng, and C. H. Tan, "InAs photodiodes for $3.43 \mu \mathrm{m}$ radiation thermometry," IEEE Sensors Journal, vol. 15, no. 10, pp. 5555-5560, 2015.

[42] "PbSe photoconductive detectors," September 2019, http:// hamamatsu.com.cn/UserFiles/DownFile/Product/p9696-02_ etc_kird1073e03.pdf.

[43] “Lasery a Optika," September 2019, http://www.lao.cz/ detektory-oem-prvky-119k/dalsi-fotodetektory-210k/pbsa-pbse-detektory-53p.

[44] ThorlabsSeptember 2019, https://www.thorlabs.com/ thorproduct.cfm?partnumber=FDPSE2X2.

[45] T. Katsumata, K. Morita, H. Aizawa, S. Komuro, and T. Morikawa, "Fiber-optic thermometer using thermal radiation and thermally excited luminescence," in 2006 SICEICASE International Joint Conference, pp. 1894-1898, Busan, Republic of Korea, 2006.

[46] Z. Zhang, K. T. V. Grattan, and A. W. Palmer, "Fiber-optic high-temperature sensor based on the fluorescence lifetime of alexandrite," Review of Scientific Instruments, vol. 63, no. 8, pp. 3869-3873, 1992.

[47] A. Augousti, K. Grattan, and A. Palmer, "A laser-pumped temperature sensor using the fluorescent decay time of alexandrite," Review of Scientific Instruments, vol. 5, no. 6, pp. 759-762, 1987.

[48] Z. Zhang, K. T. V. Grattan, A. W. Palmer, R. Summers, S. Summan, and S. Hughes, "Cr:LiSAF fluorescencelifetime-based fiber optic thermometer and its applications in clinical RF heat treatment," in Proceedings Volume 1885, Advances in Fluorescence Sensing Technology, pp. 300-305, Los Angeles, CA, USA, 1993.

[49] Z. Zhang, K. T. V. Grattan, and A. W. Palmer, "Sensitive fibre optic thermometer using Cr:Li fluorescence for bio-medical sensing applications," in 8th Optical Fiber Sensors Conference, pp. 93-96, Monterey, CA, USA, 1992.

[50] J. P. Hehir, M. O. Henry, J. P. Larkin, and G. F. Imbusch, "Nature of the luminescence from YAG: $\mathrm{Cr}^{3+}$," Journal of Physics C: Solid State Physics, vol. 7, no. 12, pp. 2241-2248, 1974.

[51] B. Henderson and G. F. Imbusch, Optical Spectroscopy of Inorganic Solid, Oxford University Press, New York, NY, USA, 1989.

[52] C. Guguschev, J. Gotze, and M. Gobbels, "Cathodoluminescence microscopy and spectroscopy of synthetic ruby crystals grown by the optical floating zone technique," American Mineralogist, vol. 95, no. 4, pp. 449-455, 2010.
[53] S. K. Gayen, W. B. Wang, V. Petricevic, R. Dorsinville, and R. R. Alfano, "Picosecond excite-and-probe absorption measurement of the ${ }^{4} T_{2}$ state nonradiative lifetime in ruby," Applied Physics Letters, vol. 47, no. 5, pp. 455-457, 1985.

[54] Z. Zhang, K. T. V. Grattan, and A. W. Palmer, "Temperature dependences of fluorescence lifetimes inCr3+-doped insulating crystals," Physical Review B, vol. 48, no. 11, pp. 7772 7778, 1993.

[55] J. He and D. R. Clarke, "Polarization dependence of the $\mathrm{Cr}^{3+}$ $\mathrm{R}$-line fluorescence from sapphire and its application to crystal orientation and piezospectroscopic measurement," Journal of the American Ceramic Society, vol. 80, no. 1, pp. 69-78, 1997.

[56] K. T. V. Grattan, Z. Y. Zhang, L. S. Grattan, and Z. Zhang, Fiber Optic Fluorescence Thermometry, Springer Science \& Business Media, 1995.

[57] Z. Zhang, K. T. V. Grattan, and A. W. Palmer, "Phase-locked detection of fluorescence lifetime," Review of Scientific Instruments, vol. 64, no. 9, pp. 2531-2540, 1993.

[58] “Alexandrite tsar stone collectors guide," September 2019, https://www.alexandrite.net/index.html.

[59] GiaSeptember 2019, https://www.gia.edu/alexandrite.

[60] K. T. V. Grattan, J. D. Manwell, S. M. L. Sim, and C. A. Willson, "Lifetime investigation of fluorescence from neodymium: yttrium aluminium garnet at elevated temperatures," Optics Communications, vol. 62, no. 2, pp. 104-107, 1987.

[61] W. P. Chen, F. F. Hu, R. F. Wei, Q. G. Zeng, L. P. Chen, and H. Guo, "Optical thermometry based on up-conversion luminescence of $\mathrm{Tm}^{3+}$ doped transparent $\mathrm{Sr}_{2} \mathrm{YF}_{7}$ glass ceramics," Journal of Luminescence, vol. 192, pp. 303-309, 2017.

[62] W. Xu, X. Gao, L. Zheng, Z. Zhang, and W. Cao, “An optical temperature sensor based on the upconversion luminescence from $\mathrm{Tm}^{3+} / \mathrm{Yb}^{3+}$ codoped oxyfluoride glass ceramic," Sensors and Actuators B: Chemical, vol. 173, pp. 250-253, 2012.

[63] L. Xing, W. Yang, D. Ma, and R. Wang, "Effect of crystallinity on the optical thermometry sensitivity of $\mathrm{Tm}^{3+} / \mathrm{Yb}^{3+}$ codoped $\mathrm{LiNbO}_{3}$ crystal," Sensors and Actuators B: Chemical, vol. 221, pp. 458-462, 2015.

[64] Y. Miyazaki, H. Aizawa, T. Katsumata, and S. Komuro, "Low temperature measurement using fluorescence thermometry," in 2008 International Conference on Control, Automation and Systems, pp. 1004-1007, Seoul, Republic of Korea, 2008.

[65] Z. Fang, Fundamentals of Optical Fiber Sensors, Wiley, Hoboken, NJ, USA, 2012.

[66] S. Yin, P. B. Ruffin, and F. T. Yu, Fiber Optic Sensors, CRC Press, Boca Raton, FL, USA, 2nd edition, 2008

[67] K. J. Peters and D. Inaudi, "Fiber optic sensors for assessing and monitoring civil infrastructures," in Sensor Technologies for Civil Infrastructures, pp. 121-158, 2014.

[68] E. S. de Lima Filho, M. D. Baiad, M. Gagné, and R. Kashyap, "Fiber Bragg gratings for low-temperature measurement," Optics Express, vol. 22, no. 22, pp. 27681-27694, 2014.

[69] G. Laffont, R. Cotillard, N. Roussel, R. Desmarchelier, and S. Rougeault, "Temperature resistant fiber Bragg gratings for on-line and structural health monitoring of the nextgeneration of nuclear reactors," Sensors, vol. 18, no. 6, p. 1791, 2018.

[70] W. Zhang, A. Gbadebo, Y. Sun et al., "Multichannel fiber Bragg grating for temperature field monitoring," Express, vol. 27, no. 2, pp. 461-469, 2019. 
[71] Q. Chen and P. Lu, Atomic, Molecular and Optical Physics: New Research, Fiber Bragg gratings and their Applications as Temperature and Humidity Sensors, Hardcover, 2011.

[72] R. Rajinikumar, K. G. Narayankhedkar, G. Krieg, M. Suber, A. Nyilas, and K. P. Weiss, "Fiber Bragg gratings for sensing temperature and stress in superconducting coils," IEEE Transactions on Applied Superconductivity, vol. 16, no. 2, pp. 1737-1740, 2006.

[73] B. Zhang and M. Kahrizi, "High-temperature resistance fiber Bragg grating temperature sensor fabrication," IEEE Sensors Journal, vol. 7, no. 4, pp. 586-591, 2007.

[74] D. Reilly, A. J. Willshire, G. Fusiek, P. Niewczas, and J. R. McDonald, "A fiber-Bragg-grating-based sensor for simultaneous AC current and temperature measurement," IEEE Sensors Journal, vol. 6, no. 6, pp. 1539-1542, 2006.

[75] J. Koch, M. Angelmahr, and W. Schade, "Arrayed waveguide grating interrogator for fiber Bragg grating sensors: measurement and simulation," Applied Optics, vol. 51, no. 31, pp. 7718-7723, 2012.

[76] A. Cusano, A. Cutulo, and J. Albert, Eds., Fiber Bragg Grating Sensors: Recent Advancements, Industrial Applications And Market Exploitation, ebook Bentham Science Publisher, 2012.

[77] A. Yan, R. Chen, M. Zaghloul, Z. L. Poole, P. Ohodnicki, and K. P. Chen, "Sapphire fiber optical hydrogen sensors for hightemperature environments," IEEE Photonics Technology Letters, vol. 28, no. 1, pp. 47-50, 2016.

[78] B. Zhang and M. Kahrizi, "High-temperature Bragg grating waveguide sensor," in Proceedings International Conference on MEMS, NANO and Smart Systems, pp. 400-404, Banff, AB, Canada, 2003.

[79] A. A. Jasim, S. W. Harun, H. Arof, and H. Ahmad, "Inline microfiber Mach-Zehnder interferometer for high temperature sensing," IEEE Sensors Journal, vol. 13, no. 2, pp. 626628, 2013.

[80] M. Xiong, H. Gong, Z. Wang, C.-L. Zhao, and X. Dong, "Simultaneous refractive index and temperature measurement based on Mach-Zehnder interferometer concatenating two bi-tapers and a long-period grating," IEEE Sensors Journal, vol. 16, no. 11, pp. 4295-4299, 2016.

[81] L. Jiang, J. Yang, S. Wang, B. Li, and M. Wang, "Fiber MachZehnder interferometer based on microcavities for hightemperature sensing with high sensitivity," Optics Letters, vol. 36, no. 19, pp. 3753-3755, 2011.

[82] T. Y. Hu, Y. Wang, C. R. Liao, and D. N. Wang, "Miniaturized fiber in-line Mach-Zehnder interferometer based on inner air cavity for high-temperature sensing," Optics Letters, vol. 37, no. 24, pp. 5082-5084, 2012.

[83] J. Zhou, C. Liao, Y. Wang et al., "Simultaneous measurement of strain and temperature by employing fiber Mach-Zehnder interferometer," Optics Express, vol. 22, no. 2, pp. 1680-1686, 2014.

[84] X. Hao, Z. Tong, W. Zhang, and Y. Cao, "A fiber laser temperature sensor based on SMF core-offset structure," Optics Communications, vol. 335, pp. 78-81, 2015.

[85] F. Zhang, J. He, X. Xu, and Y. Wang, "Highly sensitive temperature sensor based on a Mach-Zehnder interferometer created in graded index fiber," in 2018 Asia Communications and Photonics Conference (ACP), pp. 1-3, Hangzhou, China, 2018.

[86] X. Ni, M. Wang, D. Guo, H. Hao, and J. Zhu, "A hybrid Mach-Zehnder interferometer for refractive index and tem- perature measurement," IEEE Photonics Technology Letters, vol. 28, no. 17, pp. 1850-1853, 2016.

[87] H. Gong, M. Xiong, Z. Qian, C.-L. Zhao, and X. Dong, "Simultaneous measurement of curvature and temperature based on Mach-Zehnder interferometer comprising coreoffset and spherical-shape structures," IEEE Photonics Journal, vol. 8, no. 1, pp. 1-9, 2016.

[88] M. Corke, A. D. Kersey, D. A. Jackson, and J. D. C. Jones, "All-fibre 'Michelson' thermometer," Electronics Letters, vol. 19, no. 13, pp. 471-473, 1983.

[89] D. Wu, T. Zhu, and M. Liu, "A high temperature sensor based on a peanut-shape structure Michelson interferometer," Optics Communications, vol. 285, no. 24, pp. 5085-5088, 2012.

[90] L. Yuan, T. Wei, Q. Han et al., "Fiber inline Michelson interferometer fabricated by a femtosecond laser," Optics Letters, vol. 37, no. 21, pp. 4489-4491, 2012.

[91] J. Zhang, H. Sun, R. Wang et al., "Simultaneous measurement of refractive index and temperature using a Michelson fiber interferometer with a hi-bi fiber probe," IEEE Sensors Journal, vol. 13, no. 6, pp. 2061-2065, 2013.

[92] H. Cao and X. Shu, "Miniature all-fiber high temperature sensor based on Michelson interferometer formed with a novel core-mismatching fiber joint," IEEE Sensors Journal, vol. 17, no. 11, pp. 3341-3345, 2017.

[93] C. Kaczmarek, "Measurement of the temperature sensitivity of phase modal birefringence of polarization maintaining optical fibers using a Sagnac interferometer based temperature sensor," in 2015 IEEE Sensors, pp. 1-4, Busan, Republic of Korea, 2015.

[94] M. Mądry, P. Bąk, D. Kowalczyk, and E. Bereś-Pawlik, “The fiber-wireless sensor system for temperature monitoring using Sagnac-loop interferometer," in 2018 20th International Conference on Transparent Optical Networks (ICTON), pp. 1-4, Bucharest, Romania, 2018.

[95] Y. Liu, X. Jing, H. Chen et al., "Highly sensitive temperature sensor based on Sagnac interferometer using photonic crystal fiber with circular layout," Sensors and Actuators A: Physical, vol. 314, article 112236, 2020.

[96] A. Banerjee and M. Chattopadhyay, "Simulation of temperature sensor based on photonic crystal fiber using Sagnac interferometer," in 2017 2nd IEEE International Conference on Recent Trends in Electronics, Information \& Communication Technology (RTEICT), pp. 1257-1261, Bangalore, India, 2017.

[97] R. Domínguez-Cruz, D. A. May-Arrioja, R. Martínez-Manuel, and D. Lopez-Cortes, "Temperature sensor based on an asymmetric two-hole Fiber using a Sagnac interferometer," Journal of Sensors, vol. 2018, Article ID 7595106, 6 pages, 2018.

[98] Y. Cui, P. P. Shum, D. J. J. Hu, G. Wang, G. Humbert, and X. Dinh, "Sagnac interferometer based temperature sensor by using selectively filled photonic crystal fiber," in IEEE Photonics Conference 2012, pp. 743-744, Burlingame, CA, USA, 2012.

[99] Y. Zhao, L. Cai, and X.-G. Li, "High sensitive modal interferometer for temperature and refractive index measurement," IEEE Photonics Technology Letters, vol. 27, no. 12, pp. 1341-1344, 2015.

[100] Y. Yu, Q. Huang, X. Li, X. Chen, and C. Du, “An in-line fiberoptic modal interferometer for simultaneous measurement of 
twist and ambient temperature," Sensing and Bio-Sensing Research, vol. 2, pp. 38-42, 2014.

[101] J.-J. Zhu, A. P. Zhang, T.-H. Xia, S. He, and W. Xue, "Fiberoptic high-temperature sensor based on thin-core fiber modal interferometer," IEEE Sensors Journal, vol. 10, no. 9, pp. 1415-1418, 2010.

[102] Y. Wu, Y. Zhang, J. Wu, and P. Yuan, "Fiber-optic hybridstructured Fabry-Perot interferometer based on large lateral offset splicing for simultaneous measurement of strain and temperature," Journal of Lightwave Technology, vol. 35, no. 19 , pp. 4311-4315, 2017.

[103] A. Wang, S. Gollapudi, K. A. Murphy, R. G. May, and R. O. Claus, "Sapphire-fiber-based intrinsic Fabry-Perot interferometer," Optics Letters, vol. 17, no. 14, pp. 1021-1023, 1992.

[104] A. Wang, S. Gollapudi, R. G. May, K. A. Murphy, and R. O. Claus, "Advances in sapphire-fiber-based intrinsic interferometric sensors," Optics Letters, vol. 17, no. 21, pp. 15441546, 1992.

[105] Y. Zhu, Z. Huang, F. Shen, and A. Wang, "Sapphire-fiberbased white-light interferometric sensor for high-temperature measurements," Optics Letters, vol. 30, no. 7, pp. 711-713, 2005.

[106] “Texense sensors by TEXYS," June 2020, http://www.texense .com/en/ifbn-200-1200degc-fibre-optic-ir-temperaturesensor-32.html.

[107] A. PaarJune 2020, http://www.anton-paar.com/corp-en/ products/details/ruby-thermometer/.

[108] W. Wen-Qing, Z. Lei, and Z. Wei-Hua, "Temperature monitoring system of electric apparatus based on optical fiber fluorescence," in 2014 Fifth International Conference on Intelligent Systems Design and Engineering Applications, pp. 993-995, Hunan, China, 2014. 